\title{
Aptitud social de la percepción ambiental en el Parque Metropolitano Bicentenario, ciudad de Toluca, México
}

\section{Social aptitude of environmental perception in the Bicentennial Metropolitan Park, city of Toluca, Mexico}

María Estela Orozco Hernández ${ }^{1}$, Gustavo Álvarez Arteaga ${ }^{1}$ y María Antonieta Reyes Zuazo ${ }^{1}$

${ }^{1}$ Universidad Autónoma del Estado de México, Toluca, México

eorozcoh61@hotmail.com

\section{Resumen}

La urbanización inclusiva incorpora áreas verdes como estrategia para la adaptación a la variación climática, a nivel local se desconoce la capacidad social para el manejo resiliente de los parques urbanos. El estudio analiza la aptitud social a través de la percepción ambiental en el Parque Metropolitano Bicentenario. La pregunta y el constructo proponen: ¿cómo influye la percepción ambiental en la aptitud social? La aptitud social es una capacidad adaptativa condicionada por factores subjetivos y socioculturales. A través de un diseño no experimental, observación directa y un cuestionario aplicado a una muestra de visitantes y residentes, se identifica el patrón de percepción y las áreas de oportunidad para la mejora ambiental. Los resultados establecen que la aptitud social exhibe un bajo nivel de empatía e intersubjetividad, falta de participación, especialmente en estados de neutralidad e indiferencia, debido a problemas económicos y personales. Se concluye que el potencial social de la capacidad de adaptación se articula a través de juicios de valor que definen una fuerte disposición proambiental, la selección y clasificación de opciones de mejora que implican necesidades y expectativas de responsabilidad ambiental, participación social vinculada al bienestar emocional y beneficios de recreación, deporte y salud. La operación depende del sistema de decisión que organiza los programas y proyectos de mejora continua, los procesos de cooperación y negociación, y el marco regulatorio para el manejo socio-ecológico de las áreas verdes en Toluca.

Palabras clave: aptitud social, áreas verdes, parque urbano, percepción ambiental.

\begin{abstract}
Inclusive urbanization incorporates green areas as a strategy for adaptation to climate variation, at the local level the social capacity for resilient management of urban parks is unknown. The study analyzes social aptitude through environmental perception in the Bicentennial Metropolitan Park. The question and the construct propose: how does environmental perception influence social fitness? Social aptitude is an adaptive capacity conditioned by subjective and sociocultural factors. Through a non-experimental design, direct observation and a questionnaire applied to a sample of visitors and residents, the perception pattern and the areas of opportunity for environmental improvement are identified. The results establish that social aptitude exhibits a low level of empathy and intersubjectivity, lack of participation, especially in states of neutrality and indifference, due to economic and personal problems. It is concluded that the social potential of adaptive capacity is articulated through value judgments that define a strong pro-environmental disposition, the selection and classification of improvement options that imply needs and expectations of environmental responsibility, social participation linked to emotional well-being and benefits of recreation, sports and health. The operation depends on the decision system that organizes the continuous improvement programs and projects, the cooperation and negotiation processes, and the regulatory framework for the socio-ecological management of green areas in Toluca.
\end{abstract}

Keywords: environmental perception, green areas, social aptitude, urban park.

Documento recibido el 21 de mayo de 2019 y aceptado el 10 de junio de 2020

Financiamiento: Universidad Autónoma del Estado de México. Proyecto4742/2019CIB. Gestión de la resiliencia urbana respuesta al desafió climático. Aptitud socio ecológica de áreas verdes en Toluca, México.

Cómo citar: Orozco Hernández, M. E., Álvarez Arteaga, G. y Reyes Zuazo, M. A. (2020). Aptitud social de la percepción ambiental en el Parque Metropolitano Bicentenario, ciudad de Toluca, México. Revista de Urbanismo, 42, $151-175$. https://doi.org/10.5354/0717-5051.2020.56964 
La investigación forma parte del proyecto gestión de la resiliencia urbana respuesta al desafió climático. Aptitud socio ecológica de las áreas verdes en Toluca, México. Se analiza en la óptica del actor la aptitud social de la percepción ambiental, en el Parque Metropolitano Bicentenario. Tabara (2018) destaca que:

el estudio de percepción ambiental permite interpretar las causas sociales que explican la existencia, o inexistencia, de creencias, valores o actitudes culturales que mediatizan la concepción del entorno en un contexto específico. Los resultados aportan conocimiento socioambiental y acercan preferencias y percepciones sociales a los procesos de decisión política en materia de medio ambiente, el conocimiento para el medio ambiente vincula las interacciones, representaciones, percepciones y acciones de los ciudadanos. ( $p p$. $150,161)$

Interesa caracterizar lo que los usuarios saben, piensan y sienten por las problemáticas ambientales, identificar el patrón perceptual y las áreas de oportunidad, coadyuvantes a los procesos de mejora del parque urbano en estudio. Se utilizó una metodología cualitativa, la información se obtuvo de la observación directa y un cuestionario estructurado aplicado a una muestra estadística de visitantes y residentes que habitan áreas urbanas adyacentes.

En principio la aptitud o las aptitudes en las ciencias económicas y el desarrollo humano, enuncian que cada individuo tenga o desarrolle capacidades y habilidades para desempeñarse con eficacia en la actividad humana. Covarrubias (2018) distingue la aptitud como una capacidad natural, que puede ser potenciada o limitada por los contextos en los que se desenvuelven los individuos. Los factores sociales se insertan en hábitos y emociones constituidas en la infancia, el hogar, la escuela y la comunidad. Walker (2011) interpela que el punto central consiste en que cada persona desarrolle a través de la educación, una comprensión razonada de los hechos valorados de ser y actuar. Sugiere redirigir acuerdos hacia la pertenencia a la comunidad, buscar ejes en los otros e involucrarlos en la construcción de capacidades sociales. Se comprende que la aptitud social de la percepción ambiental sería una propiedad o capacidad adaptativa que se construye desde las subjetividades, los juicios de valor y las expectativas de los usuarios, para modificar conductas y emprender proyectos de acción colectiva. Este marco sitúa los determinantes intangibles y los contextos en los que se desarrollan los individuos en su relación con los sistemas ambientales.

El escalamiento de enfoques teóricos paradigmáticos de origen disciplinar distinto, expone los determinantes que vinculan el ser individual y al ser colectivo a las expresiones ambientales para fundamentar el carácter intersubjetivo del constructo aptitud social de la percepción ambiental. El hilo conductor del enfoque social de la subjetividad individual se ubica en planteamientos de la geografía de la percepción y la psicología ambiental. Marrón (1999) señala que tres décadas atrás:

la geografía sostuvo que las decisiones individuales, configuraban las acciones sociales que se expresarían espacialmente sobre el medioambiente, lo cual reforzó la observación, análisis y valoración de la conducta a través de la dimensión subjetiva de lo personal, lo vivido y lo percibido. (p. 89)

Fernández (2008) ratifica que este enfoque se alimentó de la psicología avocada al estudio de las conductas del ser humano hacia el ambiente, dando forma al estudio de la percepción ambiental entendida como la respuesta del individuo a su ambiente a través de los estímulos sensoriales. Capel (1973) concibió la percepción como un proceso interactivo debido a razones orgánicas, sensoriales o resultado del aprendizaje.

La información exterior es filtrada por el sistema de valores para elaborar una imagen ambiental bilateral entre el mundo observado y el observador, varios individuos tendrán imágenes diferentes de una misma realidad, cada uno interpreta de acuerdo con su estructura social y concepción del mundo. La percepción involucra mecanismos psicológicos- sentimientos y valoresque inciden en el comportamiento humano y en la organización de un área. El comportamiento tiene efectos en las decisiones para realizar actividades que modifican el medio real y enriquecen el medio percibido. (p. 63)

Roth (2000 afirma que las prácticas humanas y las relaciones con el entorno, asumen dos modalidades; una ubica la conducta como efecto del ambiente y otra que la 
sitúa como causa de las modificaciones de éste, por su parte, Ostrom (2000) alude a la incertidumbre de los ambientes naturales, debida a la ausencia de empatía y a los incentivos que llevan a los individuos a conductas oportunistas destructivas. Noguera de Echeverri (2007) aboga por la formación en ética ambiental y conciencia ecológica para mantener los sistemas naturales, Gómez (2010), Barberousse (2008) coligen que la empatía es necesaria para desarrollar estrategias de conservación ecológica. Briceño y Ribas (2012), Tito, Velázquez, Martínez y Cos (2013), coinciden en que la relación entre el individuo y los ecosistemas está mediada por la percepción que otorga sentido, significados y significantes distintos, cuando la valoración carece de empatía impide la conexión con la totalidad, entonces el reaprendizaje podría ser la única ventaja competitiva.

Alea $(2006$, p. 8) constata que "el diagnóstico y la evaluación de la percepción ambiental tienen por objetivo incrementar los conocimientos de las personas con relación al medioambiente, el grado de compromiso con éste e implementar conductas a su favor". En esta línea los estudios realizados en grupos focales de sistemas educativos escolarizados, primaria, secundaria y posgrado, sitios de importancia ecológica y percepción de riesgo (Arista, 2008; Zamorano, Parra, Peña, Castillo y Vargas, 2009; Cendra y Paolini, 2015; Cuervo, 2010; Mikulic et al, 2009; Morales, 2012), coinciden en que la percepción parte del contacto directo del individuo con su entorno, la interpretación y la valoración de los componentes del medioambiente, están condicionadas por factores externos e internos, los primeros tienen que ver con la condición laboral, la zona de residencia, la vida cotidiana y los cambios ambientales, los segundos con las experiencias personales, las creencias y el sentido de pertenencia, este valor puede o no estar presente, depende de cada individuo. Las variantes influyen de modo e intensidad distinta en la disposición en favor de la conservación de los ecosistemas, en las conductas y las decisiones proambientales. Los resultados identifican áreas de oportunidad para los programas de educación ambiental, protección, conservación y gestión del medioambiente y los recursos naturales, divulgación de los servicios que brindan los ecosistemas locales, gestión de la participación social y la toma decisiones.

Estimado que más de $50 \%$ de la población mundial vive en las ciudades, el ambiente urbano centra la atención. La
ONU (2017) plantea que la complejidad medioambiental en las zonas urbanas demanda procesos de planeación y gestión que permitan sumar capacidades hasta lograr la integración de iniciativas institucionales, ciudadanas y científicas. Las problemáticas abstraen las áreas verdes como estrategia de adaptación para enfrentar la variabilidad climática local y espacios idóneos para evaluar la sostenibilidad urbana. Vélez (2009); Falcón (2007); García y Guerrero (2006) y Flores (2012) reconocen en los bosques urbanos sistemas ambientales que cumplen un doble rol, ecológico y social, proporcionan servicios ambientales que impactan favorablemente en la calidad de vida. El valor ambiental lo define el aire y agua limpios, captura de agua de lluvia, amortiguamiento de temperatura y ruido, secuestro de carbono, formación de oxígeno, hábitat de flora y fauna, espacios de convivencia que tiene beneficios en la salud física y psicológica de los grupos sociales.

El enfoque sociocultural aborda la relación del individuo con el entorno natural y social. Rizo (2006) desde la interacción social y el enfoque de la sociología fenomenológica, señala que el individuo reproduce su contexto social a partir de interacciones cotidianas. La intersubjetividad, otorga relevancia a los referentes de sentido social que posibilitan el diálogo, la negociación y/o conflicto en situaciones de interacción humana. Lo social, en términos colectivos, tiene telón de fondo en la influencia de las acciones individuales en los demás. Giménez $(1999$, p. 126) y Uribe $(2014$, p. 101, 110) exploran la subjetividad e intersubjetividad a partir de la cultura y la vida cotidiana.

La cultura creación histórica y sincrónica, cruza las experiencias individuales que orientan la conducta social y las pautas de vida cotidiana que se expresan en modos de creer, percibir y actuar. Las vivencias orientan la verdad en la que cada persona cree y está inmersa, al llevar esas intersubjetividades al plano social mediante la interacción, objetivan la realidad social. La vida cotidiana influida por factores sociales, económicos y políticos entreteje la subjetividad individual, para realizar prácticas culturales en escenarios y lugares diversos. El individuo con emociones, motivaciones, intereses, deseos y necesidades da sentido a los lugares y los lugares dan sentido a las prácticas cotidianas. 
Gutiérrez Vera (2003) subraya que las fuerzas psicológicas y los valores culturales son el motor de las acciones de los individuos, por lo tanto, interesan las propiedades de los individuos no en situaciones objetivas, sino en intenciones, opiniones y sentido con el que racionalizan sus prácticas cotidianas.

En opinión de Parales y Vizcaíno (2007):

las emociones y motivaciones configuran la creación colectiva, las creencias se enriquecen y las emociones influyen las decisiones. La función evaluativa-afectiva de las actitudes pondera las interpretaciones y significados que se expresan preferencias $y$ expectativas ante situaciones problemáticas, las actitudes favorables serían campo de cultivo para la persuasión, la comunicación, el cambio y la efectividad de la organización social. (p. 81)

Vargas (1994), Roth (2000), Valera, Pol y Vidal (2015), consideran que la valoración que hace el individuo da significado a los sistemas ambientales, el significado tiene referencia en los patrones perceptivos que desencadenan respuestas emocionales. El perceptor presta atención a ciertos aspectos y pasan por alto otros, lo cual configura expectativas, conductas y decisiones con respecto al medioambiente. En la óptica metodológica, Alea (2006) propone analizar valores, percepciones, conocimientos, actitudes, sensibilidades y comportamientos. Considera que las vivencias, los conocimientos y los valores sostienen la responsabilidad para que cada individuo dimensione los problemas ambientales y oriente conductas a favor del entorno. Gomera $(2008$, p.2) delinea el sistema de vivencias, que el individuo utiliza en su relación con el medioambiente: cognitiva o grado de información y conocimiento; afectiva agrupa creencias, sentimientos o emociones, actitudinal demuestra interés y predisposición por participar y aportar mejoras; conativa o conductas que definen los comportamientos y activa expresa prácticas propias de comportamientos responsables (Figura 1 ).

\section{Figura 1}

Sistema de vivencias individuales

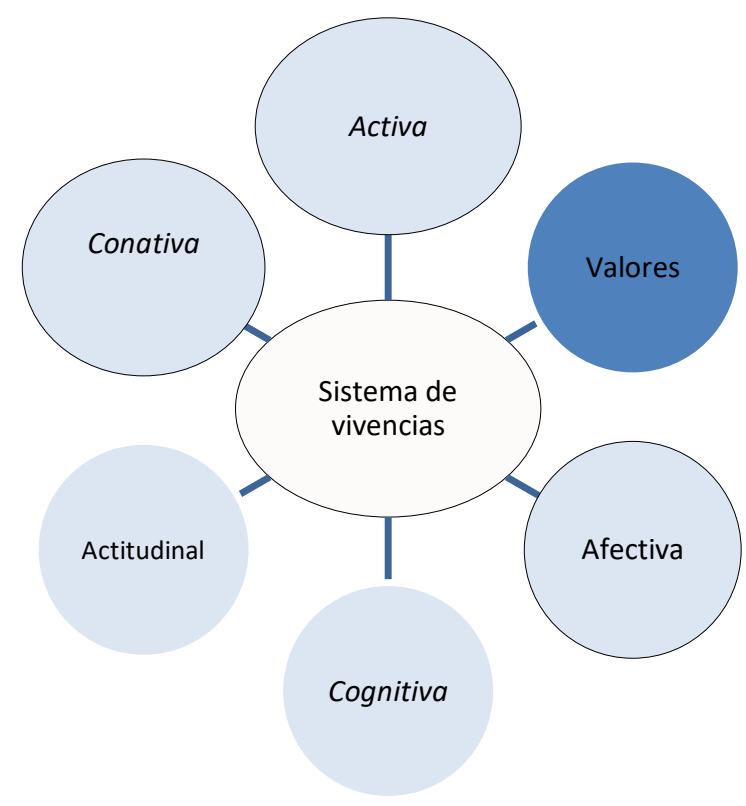

Elaboración propia con base en Gomera (2008) y Alea (2006). 
Los valores son atributos individuales, entre otros, la empatía, la responsabilidad y la sensibilidad. Valadez y Landa (2002) señalan que los valores involucran emociones y sentimientos, la sensibilidad es la apreciación individual sobre el medioambiente y los problemas inherentes, la dirección favorable o desfavorable influye en las opiniones, actitudes, comportamientos y decisiones. Ciompi (2007) en su formación experta, define que:

el afecto es un estado psicofísico de calidad, duración y grado de consciencia variable, puede ser consciente o inconsciente. Los afectos base, son la curiosidad o el interés, el miedo, el enfado, la alegría y la tristeza, según ciertos autores, el temor, el hastío y la vergüenza. Incluso la tranquilidad, la neutralidad o la indiferencia son estados afectivos que tienen efectos sobre todo pensamiento $y$ comportamiento. (p. 156)

Cabezas (2010) centra la función intersubjetiva adaptativa o social de las emociones:

estas regulan la relación del sujeto con él mismo, con su medio, con otros objetos y con otros sujetos, influyen en la razón cuando colocan atención en lo valorado como relevante, motivan el razonamiento, pone en perspectiva la información de la percepción para solucionar problemas de cooperación y logro de objetivos. (p. 78)

Si bien las emociones condicionan las conductas, no las determinan, la motivación es factor determinante de las conductas. Herrera y Zamora (2014) precisan que:

la motivación es un proceso auto energético de la persona que ejerce atracción hacia un objetivo, supone acción del sujeto y esfuerzo para conseguirlo. La motivación se compone de necesidades, deseos, tensiones, incomodidades y expectativas, es un paso previo del aprendizaje. ( $p$. 126)

Valadez y Landa (2002) indican que la función cognitiva de la percepción es moldeada por las vivencias, el grado de información y la formación escolar. Febles (2001) refiere que el conocimiento ambiental implica selección y organización de la información, este influye en los comportamientos para funcionar en la vida diaria $y$ responder a los cambios del contexto.
Parales y Vizcaíno (2007) indican que:

las actitudes son estados personales evaluativos; que vinculan el objeto actitudinal y sus atributos. La memoria media las actitudes o predisposición para actuar de manera determinada. Las actitudes expresan propiedades de estabilidad y cambio; los elementos evocados con frecuencia tienden a ser resistentes al cambio, la persuasión estaría orientada a la modificación de las actitudes. (p. 354)

Álvarez y Vega (2010) indican que las actitudes favorables al medioambiente influyen en el comportamiento, siempre que otros factores no lo impiden. Significa que actitudes y conductas no tienen relación causa efecto, debido a variables moduladoras. Laca (2005) encuentra los factores moduladores:

en las características de la situación, las actitudes en sí y la relativas a los individuos, los cuales moderan o debilitan la influencia de las actitudes sobre las conductas, por ello las actitudes se aprecian como probabilidades de ocurrencia de los comportamientos. (p. 118)

Roth (2000), (García y Restrepo, 2015) expresan las 155 propiedades valorativo-afectiva de las actitudes, las cuales predisponen acciones en relación con el objeto ecológico, pero no determinan las conductas, estas responden a estímulos externos y motivaciones internas que afectan a las personas: formación educativa, cultura- creencias, costumbres y sentido de pertenencia-, modo de vida, normas, ética, derechos e instituciones. Finalmente, el comportamiento agrupa las conductas que modifican el entorno o la relación con él, en dependencia del compromiso del individuo con su medioambiente.

\section{Métodos y materiales}

El diseño de investigación no experimental transeccional descriptivo (Hernández, Fernández y Baptista, 2014), tienen la finalidad de identificar el patrón de la percepción ambiental que condiciona la aptitud social coadyuvante de procesos de mejora en el parque urbano. El procedimiento empírico se llevó a cabo por medio de observación directa y un cuestionario aplicado a una muestra estadística de visitantes y residentes. Los visitantes agrupan personas que se desplazan para satisfacer motivaciones personales mediante una estancia 
restringida a un horario de servicio, los residentes personas que habitan áreas adyacentes.

\section{Cálculo de la muestra estadística.}

La recolección de los datos se realizó en un solo momento, mediante el diseño y aplicación de un cuestionario estructurado por cinco dimensiones: formación, conocimiento, sensibilidad, actitud y responsabilidad. EI universo se conformó por el promedio diario de visitantes, 2.900 (CGCERT, 2017) y 487 viviendas habitadas distribuidas en nueve manzanas (INEGI, 2015). El cálculo se realizó con la fórmula siguiente:

$$
n=o^{2} * p * q * N / E 2 *(N-1)+o^{2}{ }^{*} p * q .
$$

$n=$ Muestra; $N=$ Universo; $p=$ característica $a$ investigar, cuando no se conoce $50 \%$, q $=50 \%$ es complemento del universo; nivel de confianza $2=95.5 \%$ (Sierra, 1995).

Muestra de visitantes

$$
\begin{gathered}
\mathrm{n}=2^{2} * 50 * 50 * 2900=29000000 \\
11^{2} *(2900-1)+2^{2} * 50 * 50=360,779 \\
29,000,000 / 360,779=80 \\
\text { Muestra de viviendas habitadas } \\
\mathrm{n}=22 \times 50 \times 50 \times 487=4,870,000 \\
13^{2} *(487-1)+2^{2} * 50 * 50=92,134 \\
4,870,000 / 92,134=51
\end{gathered}
$$

La fracción de muestreo $(51 * 100 / 487=10,47 \%)$ se aplicó a las viviendas por manzana (№ viviendas * $10,47 \% / 100)$, para obtener el número de cuestionarios que se aplicarían a los residentes (Tabla 1).
Tabla 1

Distribución de cuestionarios por manzana

\begin{tabular}{lcc}
\hline $\begin{array}{l}\text { No. } \\
\text { Manzanas }\end{array}$ & $\begin{array}{c}\text { Viviendas } \\
\text { particulares habitadas }\end{array}$ & No. de cuestionarios \\
\hline $\mathbf{1}$ & 172 & 18 \\
$\mathbf{2}$ & 3 & 1 \\
$\mathbf{3}$ & 42 & 4 \\
$\mathbf{4}$ & 20 & 2 \\
$\mathbf{5}$ & 57 & 6 \\
$\mathbf{6}$ & 96 & 10 \\
$\mathbf{7}$ & 30 & 3 \\
$\mathbf{8}$ & 47 & 5 \\
$\mathbf{9}$ & 20 & 2 \\
\hline & $\mathbf{4 8 7}$ & $\mathbf{5 1}$ \\
\hline
\end{tabular}

Fuente: Elaboración con base en INEGI, 2016.

Los cuestionarios se aplicaron a 82 visitantes y 48 a residentes en edad mínima de 15 años y confirmaron que visitan o han visitado el parque urbano.

\section{Parque Metropolitano Bicentenario}

La ciudad de Toluca de Lerdo es el núcleo urbano de la quinta zona metropolitana del país, cuenta con 489.333 habitantes (CONAPO, 2010), 36.108 vialidades, 45\% no presentan árboles o palmeras (INEGI, 2015), dispone de $3.491 .329 \mathrm{~m}^{2}$ de áreas verdes, distribuidas en cuatro categorías de manejo: parque estatal, parque municipal, parque urbano y jardines, el área verde promedio por habitante, estima $7 \mathrm{~m}^{2}$ (Figura 2). 


\section{Figura 2}

Superficie de áreas verdes en la ciudad de Toluca

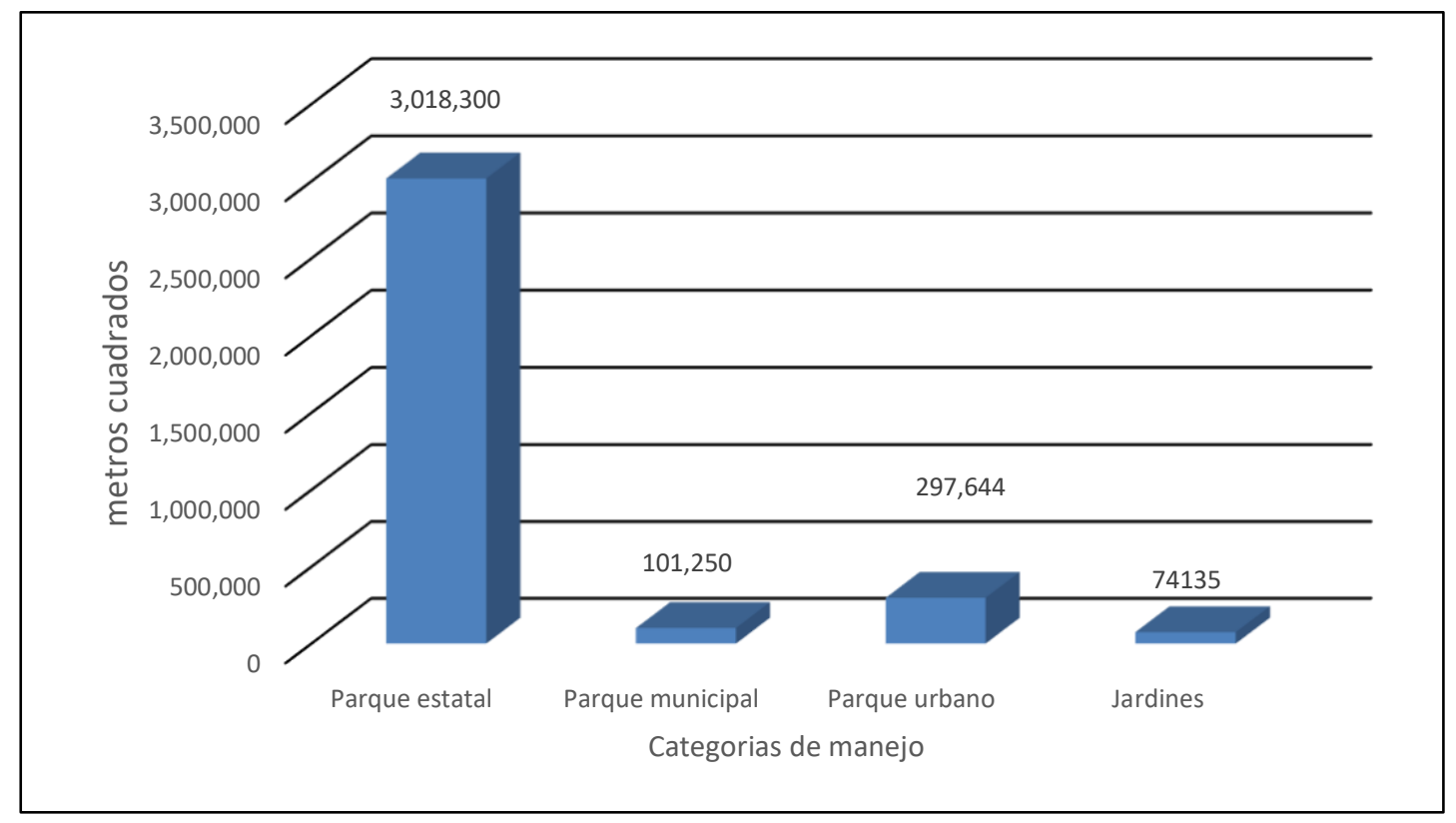

Fuente: H. Ayuntamiento Municipio de Toluca (2013).

La ciudad de Toluca cuenta con cuatro áreas verdes que ocupan superficie significativa, el Parque Estatal Sierra Morelos (29 de julio 1976, ampliación 15 de septiembre de 1981); Parque Municipal de Recreación Popular, El Calvario o Matlatzincas (20 de julio de 1988); Parque Estatal Alameda Poniente, San José de La Pila o Alameda 2000 (20 de enero de 1993, desincorporado el 12 de septiembre de 2001) y Parque Metropolitano Bicentenario, 2011 (H. Ayuntamiento Toluca, 2013). La tipología de áreas verdes citadinas varía debido a las particularidades geográficas, necesidades sociales y recomendaciones técnicas (Flores y González, 2010). EI subsistema nacional de recreación establece que los parques urbanos son espacios comunitarios, les atribuye funciones de recreación, equilibrio psicosocial y conservación del medioambiente (SEDESOL, 1999). El Parque Metropolitano Bicentenario (PMB) localizado al sur de la ciudad de Toluca, cuenta con 22,5 ha, el servicio regional define 500.000 y más habitantes, área de influencia $30 \mathrm{~km}$ o 60 minutos, compatible con usos habitacional, comercio, oficinas y servicios. Se ubica entre las avenidas Paseo Tollocan y Av. las Torres y General Álvaro Obregón, colonia Moderna de la Cruz. Con el objeto de crear una reserva ambiental que mejoraría las condiciones de habitabilidad urbana, fue decretado parque urbano, el 14 de marzo de 2017 (Figura 3). 


\section{Figura 3}

Localización y distribución de manzanas, Parque Metropolitano Bicentenario

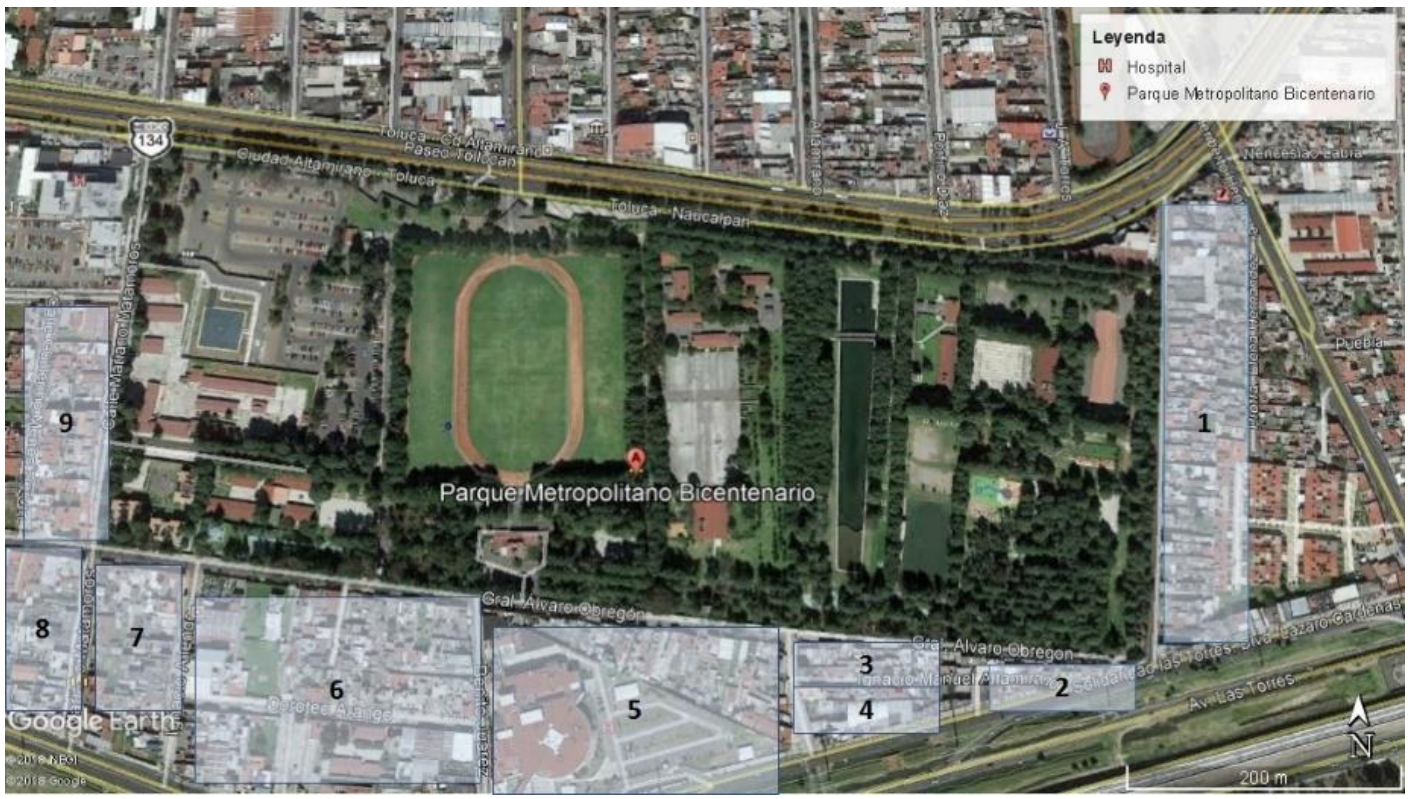

Fuente: Google Earth Pro (2019); INEGI (2016)

El equipamiento consta de acceso peatonal y vehicular, estacionamiento, auditorio, helipuerto, oficinas, sanitarios, lago artificial, explanada central, parque canino, aulas culturales, skatepark, pista de patinaje, zona fitness, zona de juegos infantiles, juegos para personas con capacidades diferentes, canchas de usos múltiples, cancha de futbol 7, zona deportiva, zona de meditación, área de picnic, área de educación ambiental, las áreas verdes ocupan nueve hectáreas o $40 \%$ de la superficie total, permanece abierto de lunes a domingo en horario de 6:00 am a 18:00 pm. Las áreas urbanas colindantes identifican el hospital materno infantil, nueve manzanas, 487 viviendas particulares, 1,911 habitantes. La cobertura de servicios de electricidad, agua entubada y drenaje es de 95\%, 93\% de las viviendas cuenta con recubrimiento en piso y sanitario, ocupantes promedio 3 a 4; habitantes en edades de 0-14 (27\%), 15-29 (30\%), 30-59 (35\%), 60 y + (8\%), escolaridad promedio diez años (INEGI, 2016).

\section{Resultados}

El análisis a través del valor de importancia que los usuarios le otorgaron a las funciones ecológicas y sociales. Se estructura en tres apartados: características de los usuarios, formación escolar y conocimiento ambiental; sensibilidad, responsabilidad y actitud ambiental; propuestas generales y selección de medidas ambientales.

\section{Usuarios, formación escolar y conocimiento ambiental.}

El conjunto de usuarios $87 \%$ cuenta edades entre 15 y 44 años, sobresalen jóvenes de 15 a 24 años (46\%), escolaridad media superior y superior (75\%). Estudiantes (41\%), trabajadores (32\%), amas de casa (19\%), 48\% acude eventualmente, $28 \%$ una o dos veces por semana, $21 \%$ una al mes, por recreación (47\%); deporte (32\%), salud (13\%) y motivos ambientales (7\%). Consideran que la afluencia es regular (45\%) y mucha (39\%). (Figura 4). 


\section{Figura 4}

Número de visitantes y residentes por rango de edad

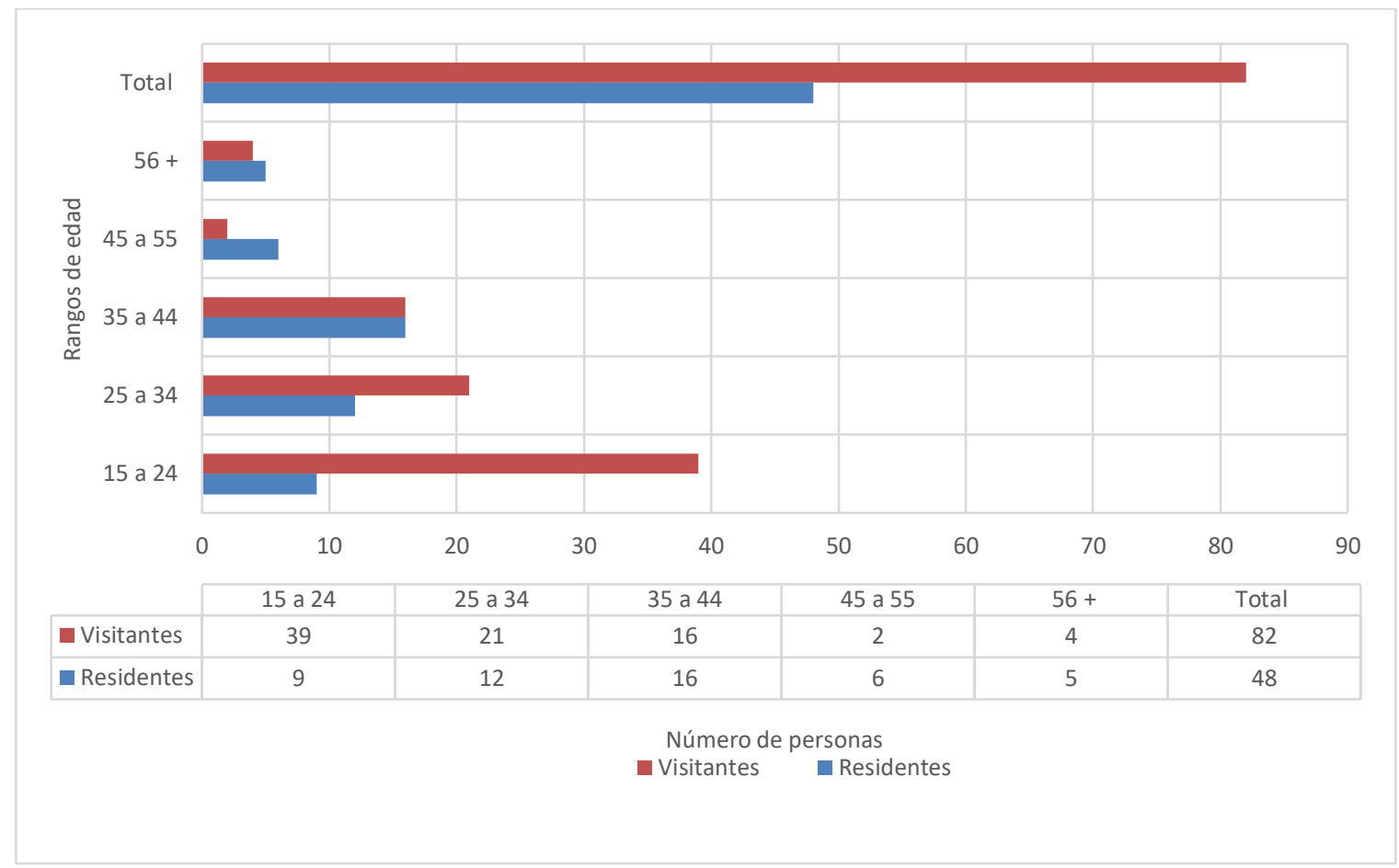

Fuente: Elaboración propia.

\section{Figura 5}

Formación ambiental escolarizada, visitantes y residentes.

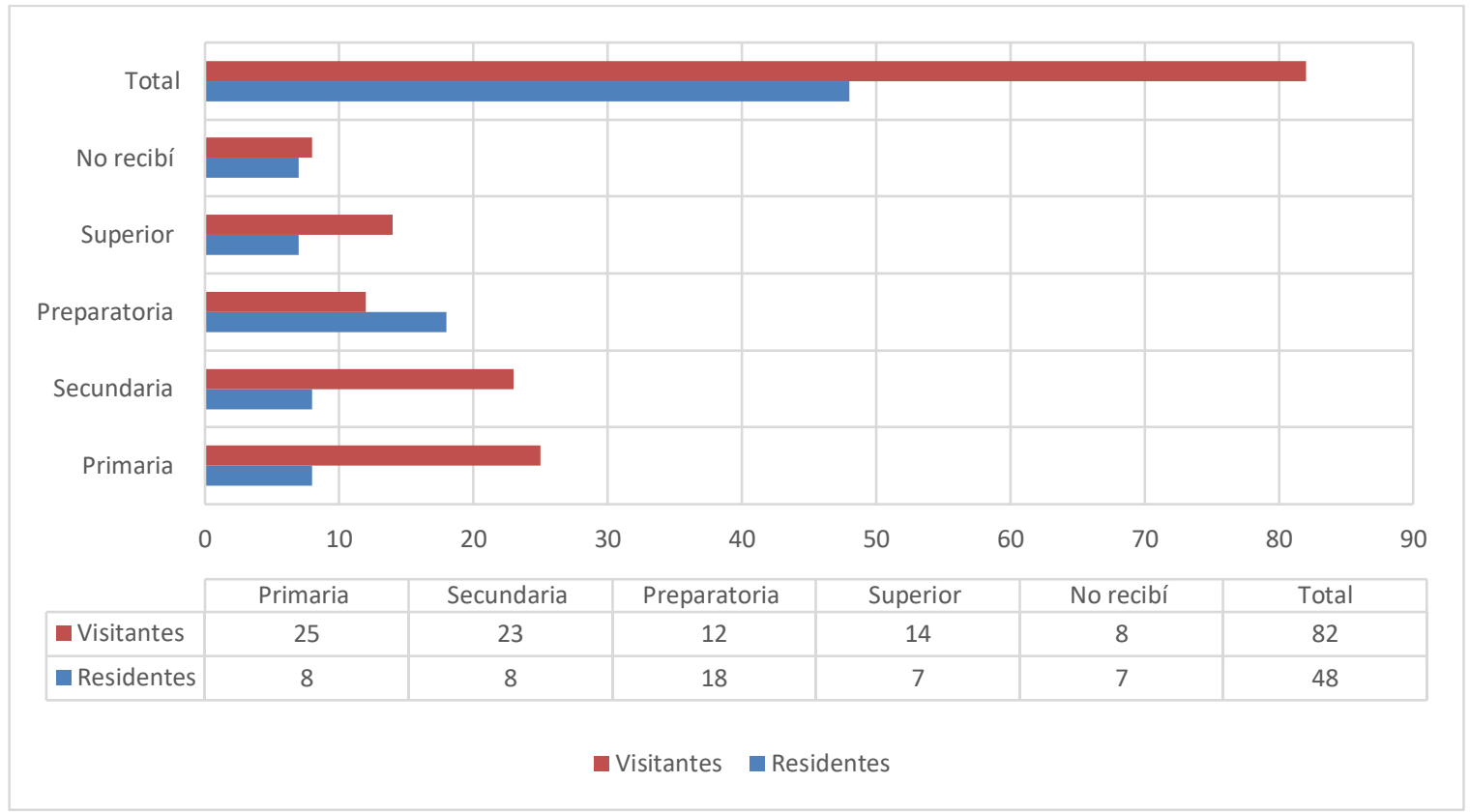

Fuente: Elaboración propia. 
Los visitantes recibieron formación ambiental en primaria, secundaria, superior, preparatoria, $10 \%$ no recibió. Los residentes en preparatoria, primaria, secundaria y superior, $15 \%$ no recibió. Sobre la calidad y suficiencia de la instrucción, no emitieron juicios, tampoco sobre las actividades ambientales aprendidas y ejecutadas en el hogar (Figura 5).

Barrón e Ysunza (2003) indican que:

la formación ambiental desarrolla habilidades que posibiliten mejor interacción del sujeto con su entorno natural y social, puede verse en el espacio escolar a través del currículo, como estrategia de concientización y formación profesional. (p. 159)

El proceso enseñanza aprendizaje debe permitir asumir el rol de ciudadanos comprometidos, sin embargo, la calidad y efectividad de la formación ambiental, los modos y medios mediante los cuales las personas la han adquirido, identifica interés o desinterés por las problemáticas medioambientales. En el caso de estudio, los entrevistados en edad de 15 a 24 y de 25 a 34 años

Figura 6

Identificación de servicios ambientales del suelo y cobertura arbórea

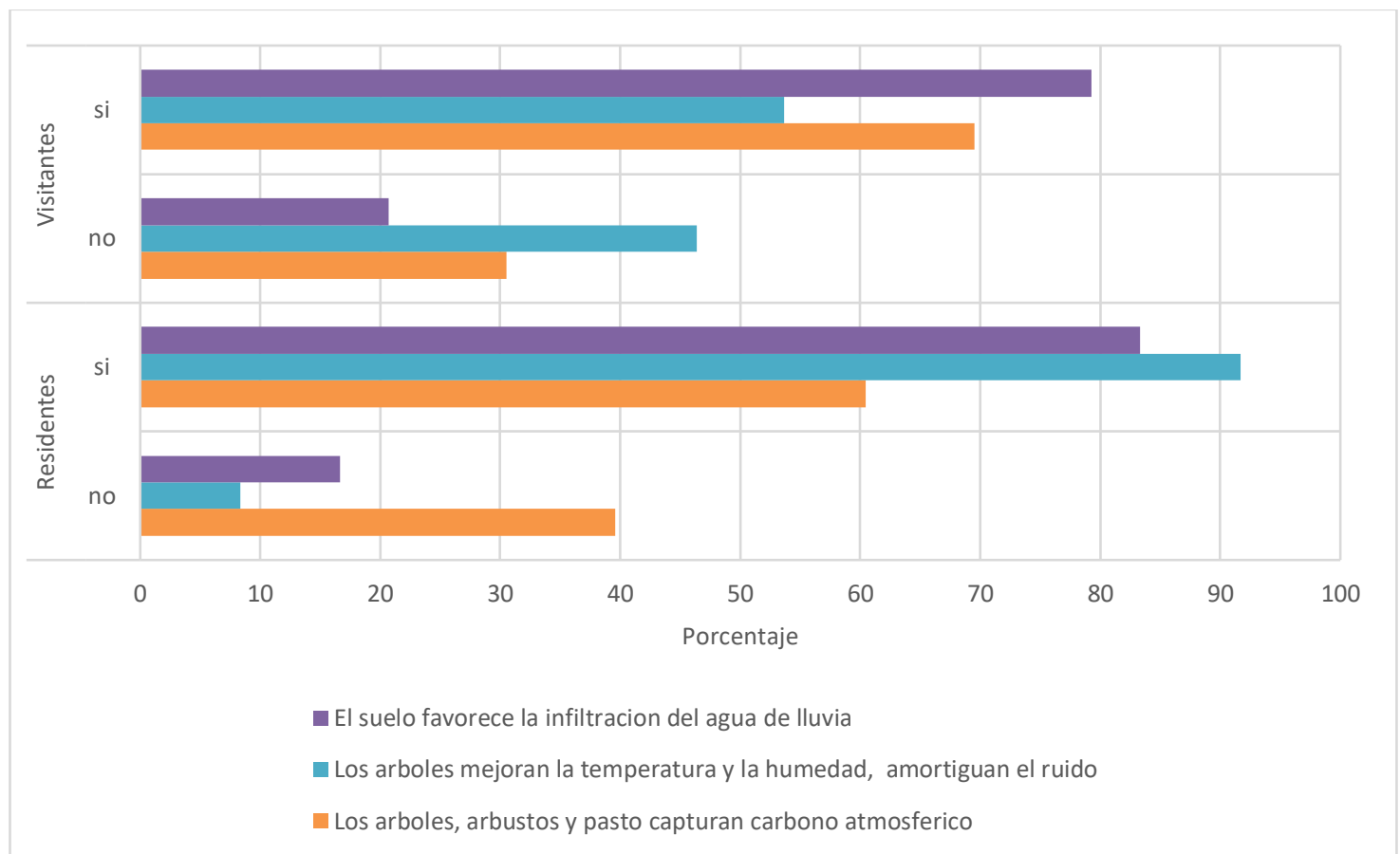

Fuente: Elaboración propia. experimentaron los cambios en el currículum de educación primaria (1990 y 2009) y secundaria (2006).

Candela, Sánchez y Alvarado (2012, p.26) y Guerra (2012, p. 79) mencionan que:

en primaria las clases en ejes temáticos dejan tiempo marginal a las ciencias naturales. En secundaria la enseñanza de la Biología, Física y Química apegada al dictado y la memoria da imagen distorsionada de la ciencia, los contenidos son complementarios y no útiles para la vida cotidiana. En el nivel medio y superior no se ha cambiado la visión del aprendizaje de la ciencia como marginal en el proceso educativo.

Aunque $36 \%$ de los entrevistados identificó los parques y las áreas verdes como parte del medio ambiente y coinciden en que son muy importantes para la conservación medioambiental (90\%), el conocimiento ambiental que poseen expresó acuerdo y acuerdo total $66 \%, 18 \%$ algo de acuerdo e indiferencia $16 \%$, saben que el suelo infiltra agua de lluvia, la vegetación captura CO2, regula temperatura, humedad y ruido (Figura 6 ). 
Los residentes no conocen norma o iniciativa para conservar el medioambiente del parque urbano, solo $4 \%$ de los visitantes conoce. Si bien, reconocen las funciones ambientales, otorgan importancia a la recreación, deporte y beneficios en salud (Figura 7).

\section{Figura 7}

Valor de importancia de las funciones ambientales del parque urbano

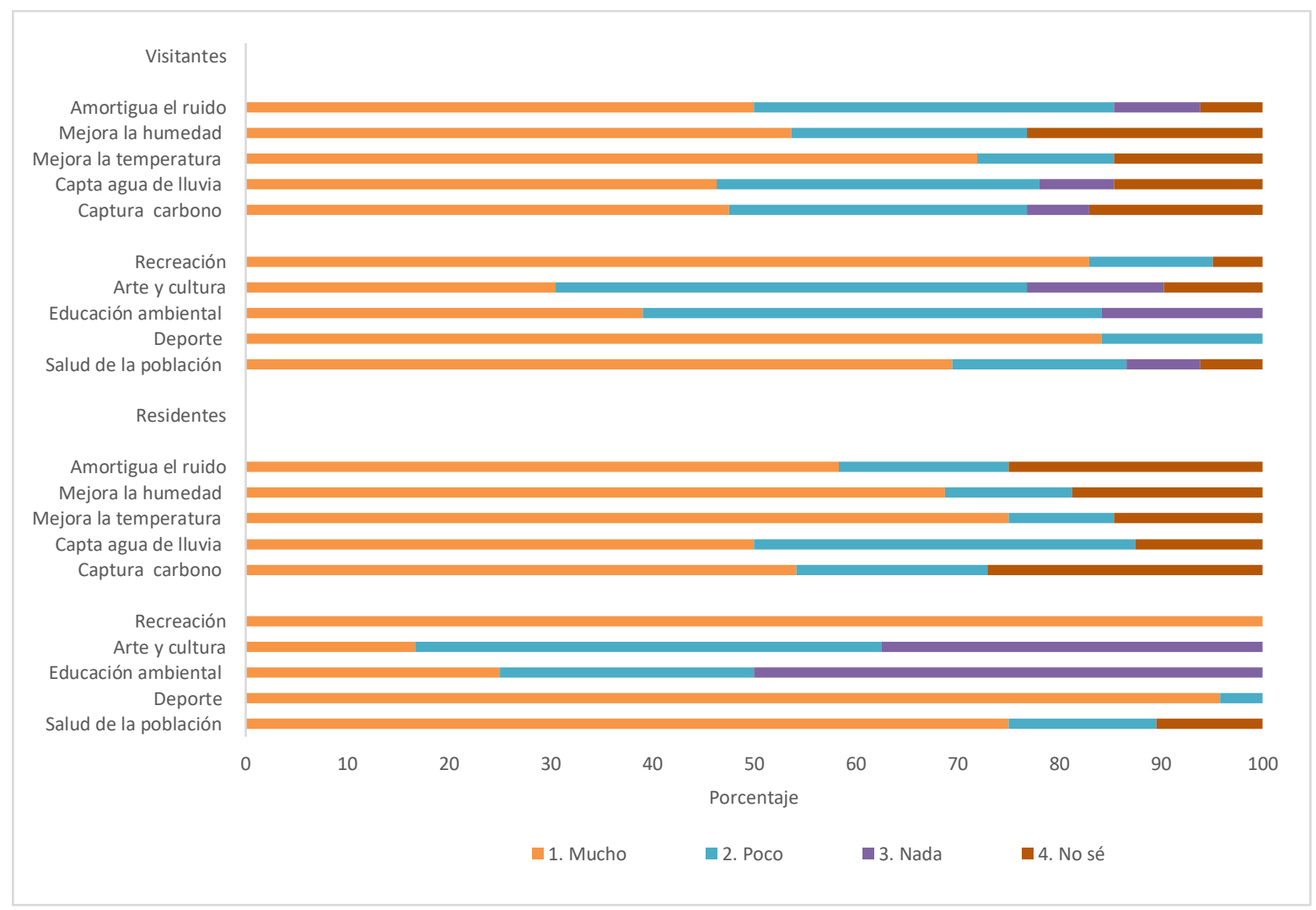

Fuente: Elaboración propia. 


\section{Sensibilidad, responsabilidad y actitud ambiental}

Los usuarios identificaron problemáticas cercanas a su vida cotidiana, los visitantes económicas, sociales y culturales, los residentes económicas y personales, menos interés por las ambientales, políticas y demográficas (Figura 8).

\section{Figura 8}

Apreciación de las problemáticas de interés

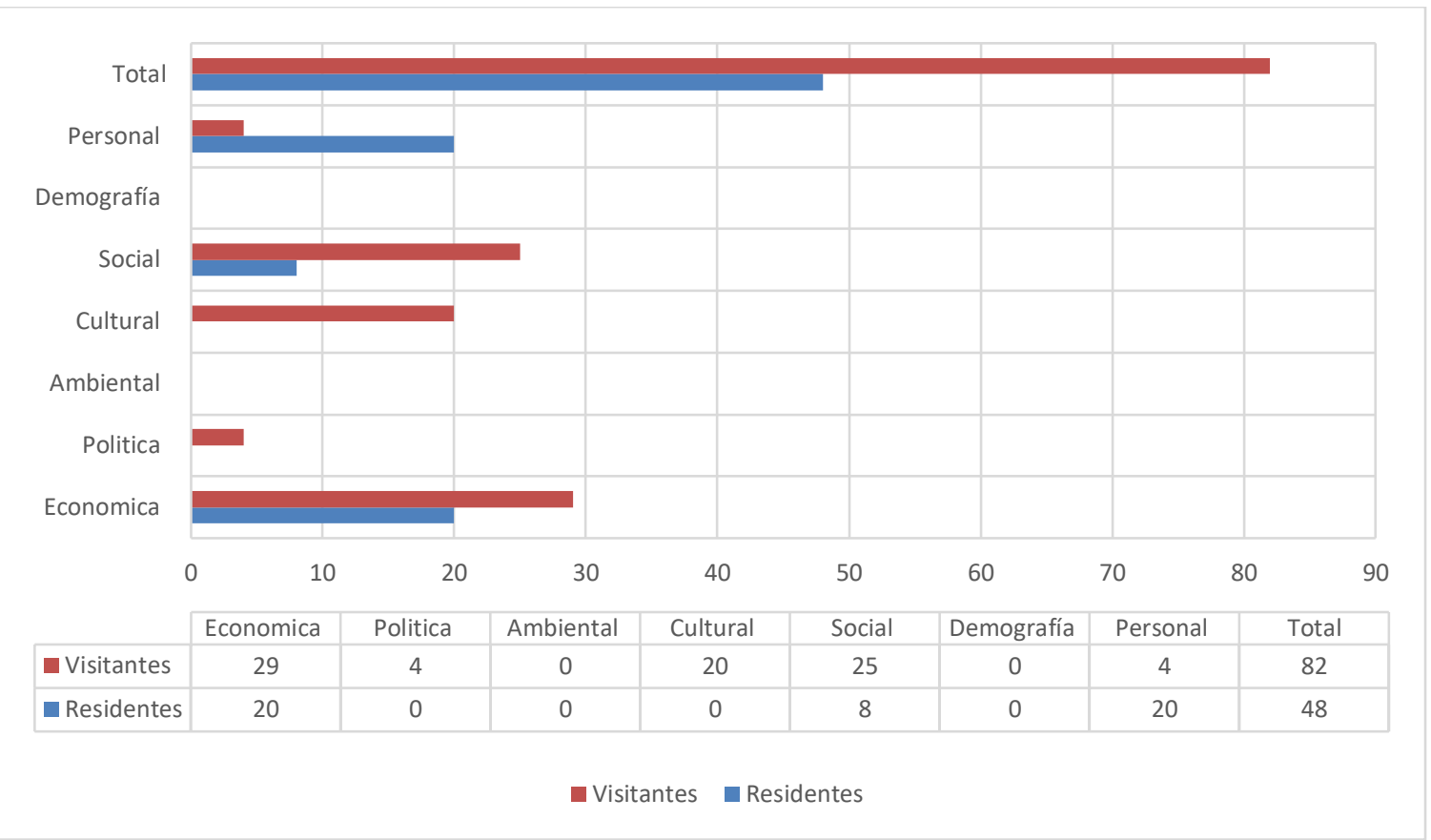

Fuente: : Elaboración propia. 
Las expectativas en veinte años dirigen el interés de los visitantes por las económicas y ambientales, sociales y personales, política cero. Los residentes las económicas, ligero interés ambiental, desinterés en política, cultura, social y demografía. Identificaron comportamientos perjudiciales uso excesivo del coche, no separación de residuos sólidos y orgánicos, consumo excesivo de energía y bienes innecesarios (Figura 9).

\section{Figura 9}

Reconocimiento de problemáticas del parque urbano

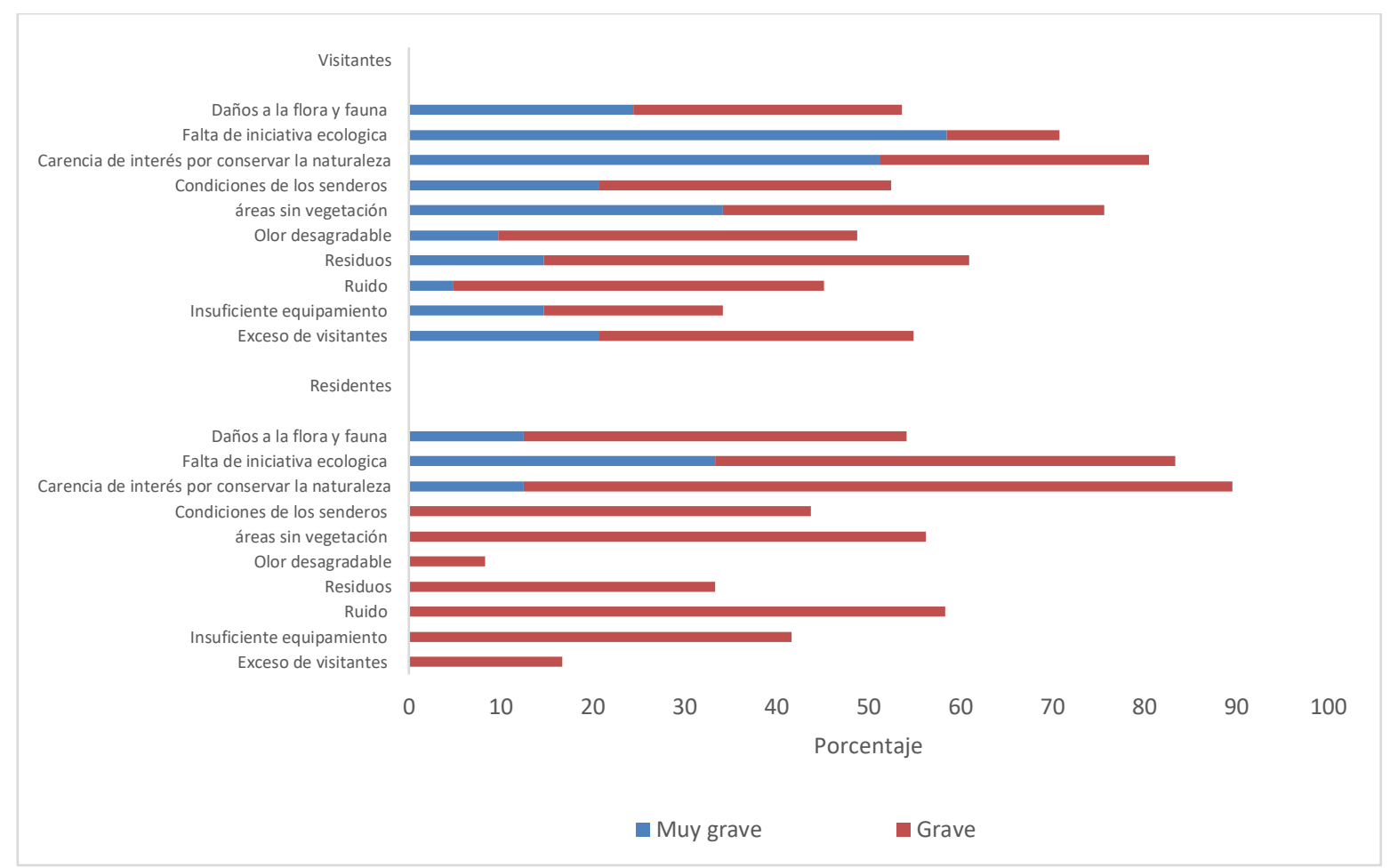

Fuente: Elaboración propia. 
No hubo juicios sobre la relación medioambiente, bienestar social y crecimiento económico, y la preocupación por el desequilibrio ambiental. Las problemáticas graves y muy graves resaltan la carencia de iniciativa ecológica e interés por conservar la naturaleza, daños a la flora y fauna, áreas sin vegetación, ruido, residuos y mal estado de los senderos (igura 10).

\section{Figura 10}

Calidad de las instalaciones y condiciones del PMB

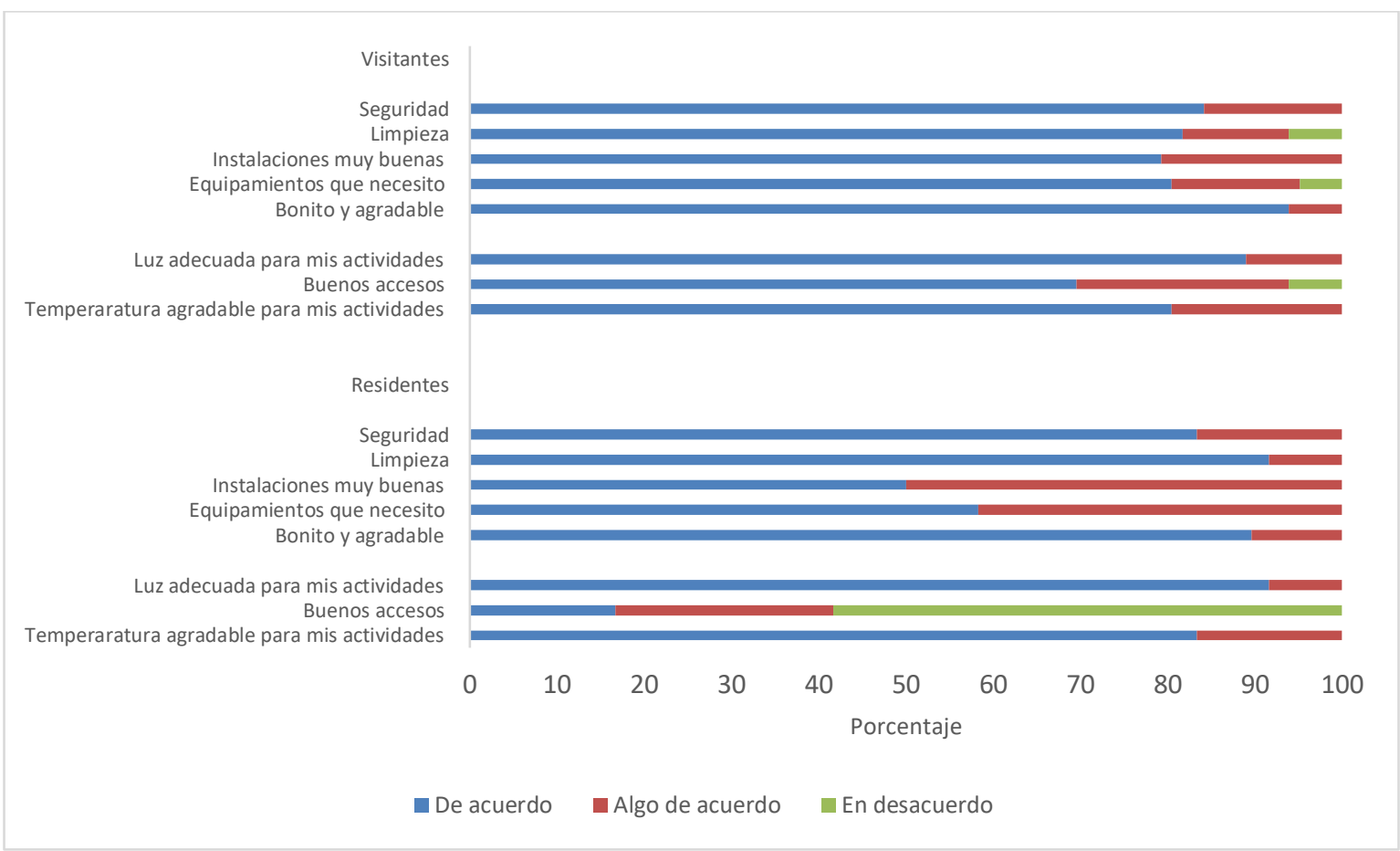

Fuente: Elaboración propia. 
Respecto a las instalaciones expresaron acuerdo en la seguridad, limpieza, belleza, luz y temperatura agradable para realizar sus actividades. Acuerdo parcial en el equipamiento que necesitan y en la eficiencia del acceso peatonal y vehicular.

Los residentes opinan que el parque ha beneficiado definitivamente (67\%), los demás consideraron la posibilidad. Coinciden en que es muy seguro y lugar propicio para el deporte, queda cerca para distraerse y convivir en familia, promueve las actividades recreativas, es un pulmón ambiental y embellece el paisaje. La vegetación regula la temperatura en la calle y en las casas habitación, mejora la calidad del aire, amortigua inundaciones y disminuye el agua que se acumula en las calles, desconocen alergias ocasionadas por el polen. Los visitantes consideran que el cuidado del parque es responsabilidad de todos (82\%), los residentes asumen responsabilidad individual (90\%), en ambos casos, $18 \%$ y $10 \%$ atribuyen la responsabilidad a los administradores. Los visitantes se manifestaron satisfechos con el equipamiento y estado ambiental (85\%), los residentes están satisfechos y muy satisfechos (64\%), regular y nada satisfechos (36\%) (Figura 11).

\section{Figura 11}

Identificación de efectos positivos y negativos del PMB

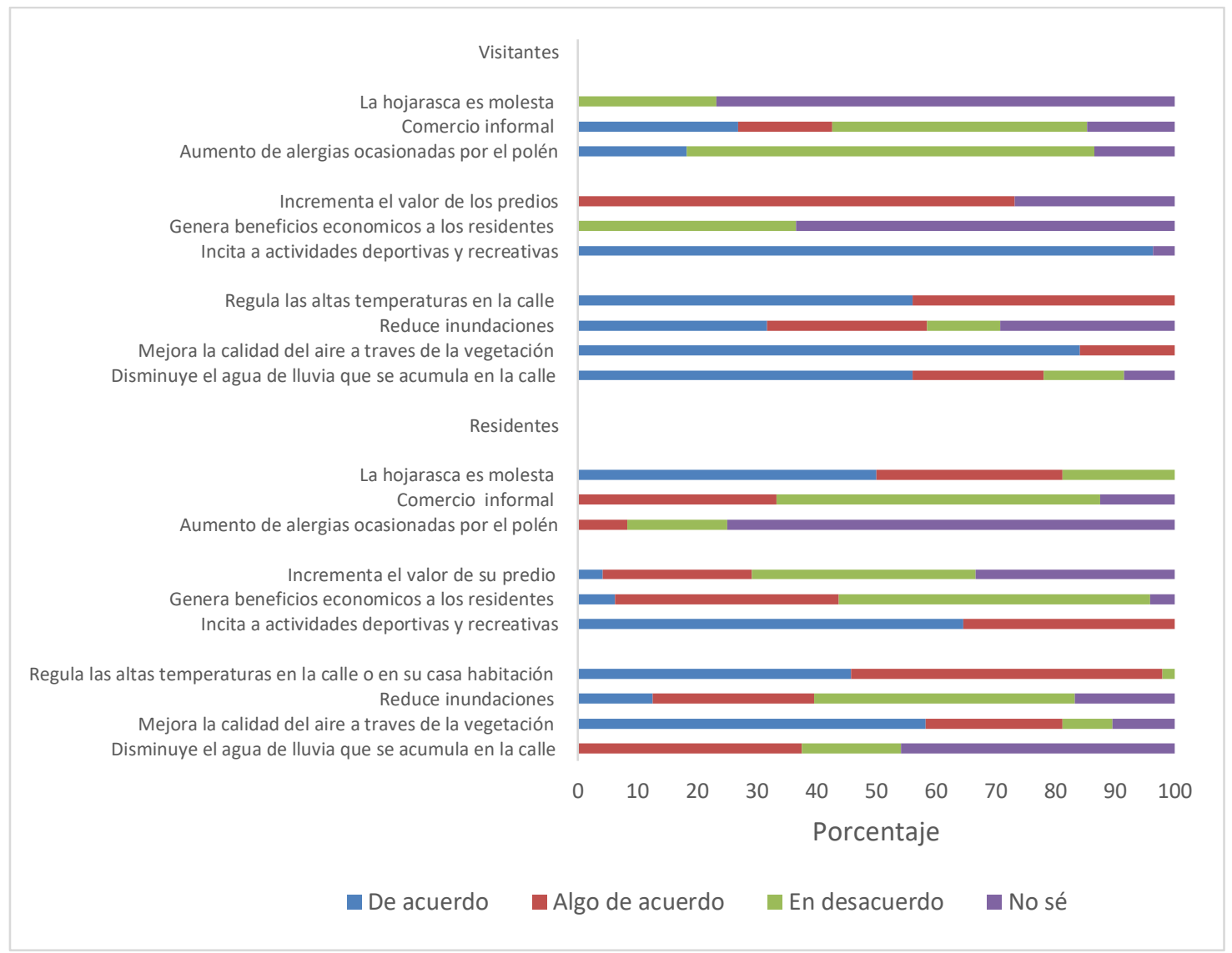

Fuente: Elaboración propia. 
Es importante la proporción de residentes (60\%) y visitantes (78\%) que expresaron disposición al pago para la conservación del parque urbano, aportarían de 1 a 5 y de 5 a 10 pesos por visita, el restante señaló que le compete a la administración, puesto que se le asigna presupuesto. Residentes (90\%) y visitantes (76\%) expresaron les gustaría aprender salud ambiental, energía, consumo ecológico, espacios protegidos, flora y fauna, el tema de los residuos no es significativo. Los visitantes no saben si la hojarasca es perjudicial, los residentes la aprecian molesta, ambos atribuyen el comercio formal e informal, a la afluencia de visitantes y a los usuarios del hospital materno-infantil adyacente y no existe consenso sobre los beneficios económicos e incremento de valor del suelo. En contrasentido, 56\% de los residentes dijo haber presenciado inundaciones, destrucción de pavimento y explosión de coladeras, el ruido en los eventos masivos es molesto. Solo $6 \%$ se dijo afectado por las actividades que se realizan en el parque, la hojarasca que tapa las alcantarillas provoca que se inunden algunas casas de la calle Antonio Albarrán.

\section{Propuestas y jerarquización de medidas ambientales}

Residentes (73\%) y visitantes (91\%) están de acuerdo en incrementar las áreas verdes para mejorar las condiciones ambientales de la ciudad de Toluca. Sugieren equipar los jardines y parques con instalaciones deportivas, el deporte lo consideran una buena estrategía para promover los espacios verdes y su cuidado, camellones y techos verdes, talleres para niños, arborización en las avenidas principales, talleres ambientales, separación de residuos e información para la concientización y conservación de los espacios verdes. Las medidas ambientales listadas en orden indeterminados en el cuestionario. Se presentan de acuerdo a la elección, importancia y jerarquización dada por los usuarios, sobresale la participación social, cumplimiento de las normas, las sanciones, reforestación, inventario de flora y fauna y regulación de la capacidad de carga (Figura 12).

Cerati y Queiroz (2016) afirman que la participación es un derecho ciudadano que requiere un marco legal para que las propuestas lleguen a los niveles de gobierno. El paso de la propuesta a la acción se materializa a través de un proceso de gestión participativa que vincula las instituciones y la comunidad, para alcanzar metas consensuadas. Requiere comprender la percepción de los ciudadanos sobre los problemas ambientales, mediante reuniones periódicas para planificar acciones a seguir. La capacitación en relación con la organización de las acciones colectivas; arroja resultados significativos que mejoran la calidad social y ambiental en un área de conservación urbana. 


\section{Figura 12}

\section{Valor de importancia medidas de mejora ambiental}

Visitantes

1. Participación de los visitantes

2. Zonificacion de áreas de fragilidad

3. No dejar desperdicio

4. Reforestación

5. Sanciones

6. Programa de interpretación de la naturaleza

7. Cumplir con las normas

8. Señalización de áreas

9. Saneamiento forestal

10. Campañas de concientizacion

11. Impuesto ecologico

12. Cerrar un dia

13. Inventario de flora y fauna local

14. Determinar la capacidad de carga

15. Saneamiento del cuerpo de agua

Residentes

1. Participación de los visitantes 2. Señalización de áreas

3. Reforestación

4. Sanciones

5. Campañas de concientizacion

6. Cerrar un dia

7. Cumplir con las normas

8. Programa de interpretación de la naturaleza

9. Zonificacion de áreas de fragilidad

10. Saneamiento forestal

11. No dejar desperdicio

12. Inventario de flora y fauna local

13. Saneamiento del cuerpo de agua

14. Impuesto ecologico

15. Determinar la capacidad de carga
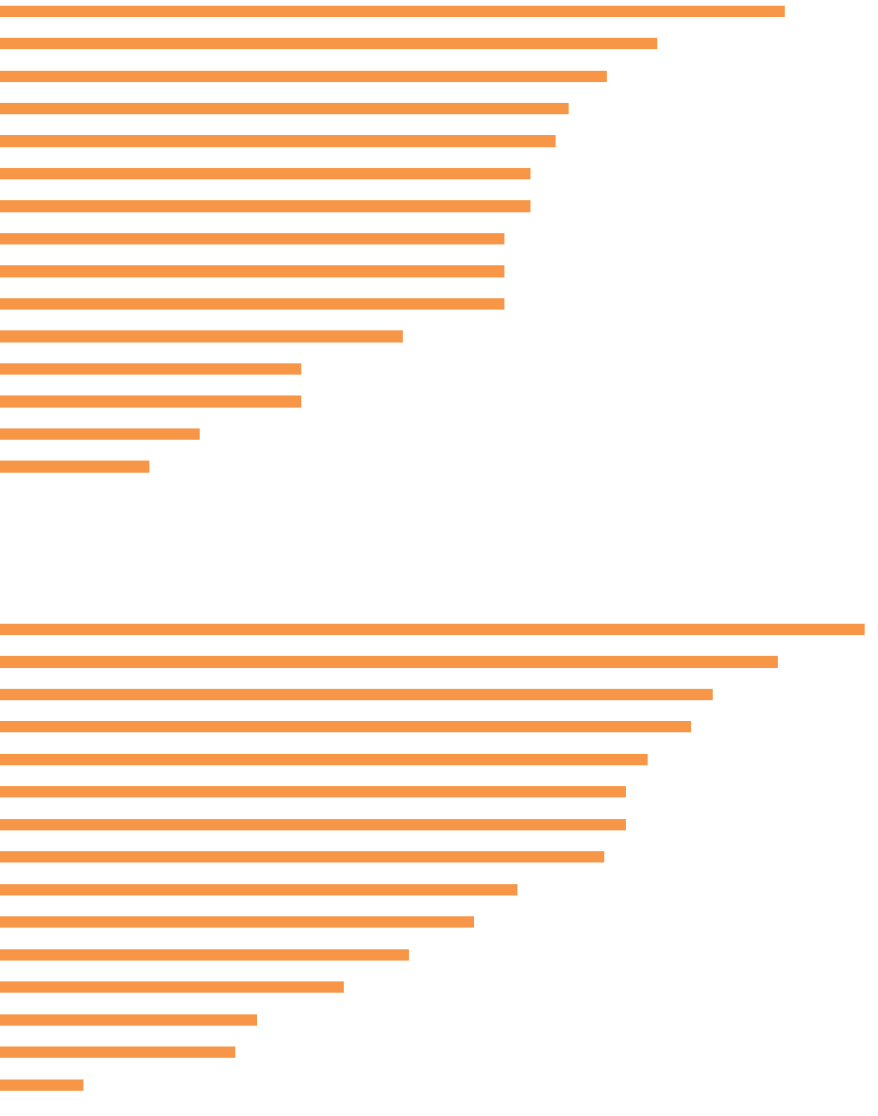

167

$\begin{array}{lllllllll}0 & 10 & 20 & 30 & 40 & 50 & 60 & 70 & 80 \\ & \text { Porcentaje } & & & & & & \end{array}$

Fuente: Elaboración propia. 


\section{Tabla 2}

Estimación de la capacidad de carga de visitantes

\begin{tabular}{|c|c|c|}
\hline Domingo 06 de mayo, 2018 & 4 domingos/mes & 48 domingos al año \\
\hline 840 & 3.360 (tres horas) & 161.280 (tres horas) \\
\hline $840 \times 360$ días año & 302.400 (tres horas) & 3.628 .800 (doce horas) \\
\hline
\end{tabular}

Fuente: Elaboración propia.

Las normas enuncian las reglas de cumplimiento obligado, contienen juicios de valor moral y social. Las reglas formalizan las normas de conducta y las sanciones en caso de incumplimiento. Los usuarios desconocen de la existencia de reglamento alguno, pero están de acuerdo en que cumplir con ciertas normas de conducta es básico para mantener el estado ambiental y la operación del parque urbano.

La reforestación es una propuesta debida a que los usuarios observaron poca densidad arbórea y zonas desprovistas de vegetación. Mañon de la Cruz, Orozco y Mireles (2018) reportaron 2.396 árboles, 40\% jóvenes, $36 \%$ maduros y $24 \%$ seniles, estimaron 298 árboles/hectárea o 33,6 $\mathrm{m}^{2}$ por árbol. Las especies introducidas, Cupressus lusitánica (cedro blanco), Pinnus cembroides (pino piñonero), aportan $70 \%$ y $13 \%$ de las existencias de árboles, el resto conforma una cubierta heterogénea de los géneros Quercus y Abies, especies exóticas de origen australiano; Eucalyptus camaldulensis (eucalipto rojo) y Eucalyptus globulus (eucalipto azul) y asiático Ficus benjamina (laurel de la india), Salyx babilónica (sauce llorón) y Populus alba (álamo blanco). Se desconoce la composición y estatus de la fauna local.

La regulación de la capacidad de carga requiere normar la cantidad máxima de visitantes que sostenga el espacio físico y ecológico del parque urbano. En el período 2013-2018 los datos oficiales hasta el mes de mayo reportaron 5.807.940 visitantes, 1.084 .921 promedio anual, la capacidad de carga promedio anual, 5 personas por $\mathrm{m}^{2}$, en cinco años y cinco meses 26 personas por $\mathrm{m}^{2}$. La afluencia promedio anual duplica la población de la ciudad de Toluca y representa $56 \%$ de la zona metropolitana. En contraste se realizó un conteo en tres horas de 9:00-12:00 am el domingo 06 de mayo de 2018, temperatura ambiente 18 grados, medio nublado.
Ingresaron 580 personas caminando y 260 en automóvil, total 840. El horario de servicios 6:00-18:00 dividido en cuatro fracciones de tres horas, indica lo siguiente (Tabla 2).

La capacidad de carga anual estima 16 personas por $\mathrm{m}^{2}$ en doce horas, los límites dependen de la variación del número de visitantes, el día de que se trate y los efectos acumulativos que se producen a consecuencia del uso continuo de los espacios del parque. Morales (2011) señala que los valores individuales y el comportamiento de los usuarios es pieza clave para mitigar el deterioro de infraestructura y espacios verdes.

\section{Discusión}

168

Los entrevistados reconocen la formación ambiental escolarizada, $10 \%$ y $15 \%$ no la recibió y no emitieron juicios sobre la efectividad y calidad de esta. En el conjunto prevalece la escolaridad media superior y superior (75\%). Padilla y Sotelo y Luna Moliner (2012) identificaron percepciones ambientales distintas según los patrones de interacción social de los individuos, dados por su actividad socio productiva y nivel educacional. Los grupos de profesionistas, estudiantes, técnicos y empleados detectaron los problemas ambientales, debido a los niveles educacionales que les permiten establecer las dinámicas que evidencian mayores impactos en escenarios turísticos. La percepción ambiental de los estudiantes no implica conocimiento de lo normativo, ello niega la existencia de una normatividad ética básica. Gomera (2008) precisa que la hipermetropía ambiental manifiesta cómo los estudiantes otorgan peso a los problemas ambientales en su círculo de preocupación, pero no los consideran en su círculo de influencia.

En la postura de Rivera y Rodríguez (2009) la educación ambiental escolarizada o para la concientización promueven comportamientos proambientales que 
adolecen de la dimensión afectiva que permitiría internalizar el conocimiento reflexivo y la participación activa en los problemas ambientales. Díaz (2006) crítica el conocimiento escolar descontextualizado, argumenta que los contextos de aprendizaje y enseñanza otorgan facilidades o imponen restricciones al desarrollo de los actores, propone la enseñanza situada, aprendizaje experiencial y enseñanza reflexiva para la acción, lo cual requiere cambios en las prácticas de enseñanza.

Los entrevistados coinciden en la importancia de los parques y las áreas verdes para la conservación ambiental urbana, sin embargo, el conocimiento sobre ellas segmenta el sector que conoce y los sectores que expresaron conocimiento parcial e indiferencia (34\%). Lo anterior podría estar condicionado por la desconexión de la información y los referentes empíricos de los componentes ambientales y de manera específica por la frecuencia de visita, los intereses y el tiempo de estancia, la mayoría realiza visitas eventuales, en las proximidades los residentes se desplazan en 5' y 10', los visitantes en $30^{\prime}$ y 60' (69\%), recorren de 15 a $30 \mathrm{~km}$, la estancia varía de una a cinco horas.

Los usuarios valoran significativamente las funciones recreativas y deportivas, y los beneficios en la salud, las consideran cercanas a su desarrollo personal. La apreciación es convergente con el ocio activo que tiene beneficios corporales y metabólicos, en esta perspectiva los factores ambientales de la urbanización se califican desalentadores de las actividades al aire libre, el miedo a la violencia y a la delincuencia, tráfico denso, mala calidad del aire y contaminación, insuficientes parques e instalaciones deportivas y recreativas (OMS, 2018). Sin embargo, la satisfacción que expresaron los usuarios sobre la accesibilidad, las condiciones de equipamiento y el estado ambiental, y la importancia que otorgan a la recreación y al deporte, supone un estado emocional de bienestar. Vargas y Roldán (2018), señalan que:

el bienestar es contingente en presencia o ausencia de factores perturbadores, el ruido, congestión, delincuencia y percepción de inseguridad, indica que un parque puede ser fuente de amenidades 0 des amenidades con lo cual el bienestar no sería inequívocamente lineal. Concluyen que los parques mejoran el bienestar de la población urbana y su efecto potencial es mayor si se intervienen factores asociados a los usos que generan insatisfacción. (p. 185)

Lupano y Castro (2010) argumentan que:

el bienestar subjetivo deriva del compromiso con la tarea efectiva y la capacidad de experimentar, ello se alcanza mediante la realización de actividades con un significado y un propósito, que no sean aburridas o estresantes, la ecuación habilidades personales y características de la tarea, exige esfuerzo y trabajo. (p. 48)

Esta bifurcación abre una línea de atención sobre las vivencias, sentimientos, emociones y el bienestar que experimentan los usuarios mediante la recreación y el deporte, para promover a través de estrategias cercanas la participación activa para la conservación y mejora del medioambiente.

El conocimiento de las funciones ecológicas del parque urbano es informativo, expresa apreciación externa de los servicios de los árboles y el suelo, regulación, control de inundaciones, regulación de la temperatura y la humedad, mitigación de la contaminación atmosférica y acústica, captura de carbono atmosférico y desconocimiento de los procesos ecosistémicos. Esta circunstancia no es atribuible a los usuarios, en la óptica del observador, pueden ser más o menos evidentes, tal es el caso de los servicios de soporte, fotosíntesis, formación y almacenamiento de materia orgánica; ciclo de nutrientes; creación y asimilación del suelo y neutralización de desechos tóxicos (MEA, 2005). El conocimiento comprensivo de los servicios ambientales de regulación y soporte requiere mediciones in situ, lo cual rebasa la percepción de visitantes eventuales sujetos a una estancia restringida.

Si bien reconocen la responsabilidad ambiental en primera persona, esta se manifiesta en intención y no como compromiso. Resaltan la gravedad de la carencia de iniciativa ecológica, interés por conservar la naturaleza, los daños a la flora y fauna, y las conductas que afectan el medio ambiente. Ello se interpreta como acciones inherentes a las conductas de los otros, en lo individual no las perciben como situaciones que les afecten directamente. Álvarez y Vega, 2010) expresan que la sensibilidad social hacia la defensa del medioambiente parece no haberse traducido en comportamientos específicos 
Durán, Alzate, López y Sabucedo (2007) sostienen que:

la inconsistencia entre actitudes y conductas se debe a la falta de concienciación por los problemas ambientales. En la medida que el individuo experimenta directamente efectos indeseables, la activación emocional se incrementa y las acciones para cambiar la situación. Las vivencias personales activan sentimientos y emociones, que motivan al individuo a tomar conciencia de sí mismo y de los peligros del entorno para actuar en consecuencia. (pp. 294-295)

Sin embargo, la experiencia individual situada no conduce de facto a la toma de conciencia ambiental, esto se explica por los conflictos que se producen entre los valores aprendidos en los contextos en los que cada individuo se ha desarrollado $y$ el conocimiento escolarizado que induce conductas reactivas que se pretende apliquen en la vida diaria, aunado a contingencias económicas personales y estrés emocional que producen, el desinterés no solo es atributo de problemáticas ambientales, más de problemáticas sociales y políticas.

Contreras y Esguerra (2006) plantean que las motivaciones y las capacidades potencian el desarrollo de los individuos, para tomar ventaja de las oportunidades. Si esto es así, las oportunidades se encuentran en desarrollar conocimientos y habilidades en favor del medio ambiente en general y en entornos cercanos a los individuos.

Las propuestas de los usuarios comprenden arborización de avenidas principales, revegetación de camellones, techos verdes, equipamiento y actividades deportivas vinculadas al cuidado de las áreas verdes, adaptación de las conductas de los usuarios, amonestar y sancionar depósitos de residuos sólidos, orgánicos y detritos de construcción en vialidades y terrenos baldíos. La identificación, ordenación y jerarquización de las opciones de mejora configura un abanico de expectativas básicas para un programa verde. Las líneas de atención agrupadas en competencias fungen como interfaces de la planeación y la intervención a través de proyectos de manejo e incremento de áreas verdes.

\section{Competencia técnico-científica}

Esta competencia abre una ventana de oportunidad para realizar estudios que determinen el estado ambiental de los componentes biofísicos y ecológicos para proporcionar servicios ambientales. Estado de los componentes biofísicos e infraestructurales; inventario de flora y fauna, determinación de la capacidad de carga y las condiciones del equipamiento. Medición de la aptitud ecológica del suelo y la vegetación, mediante parámetros de infiltración de agua en suelo, temperatura y humedad ambiente, presión acústica interior y exterior, almacenes de carbono aéreo y edáfico. Zonificación y señalética de las áreas frágiles y áreas de usos permitidos. Reforestación, saneamiento forestal, saneamiento del lago artificial y preservación de la fauna local.

\section{Competencia de gestión local}

Reglamentar las normas de conducta, prohibir el material plástico, implementar sanciones en especie y económicas, cerrar un día a la semana para mantenimiento. Establecer convenios con las instituciones de educación superior y sector privado, determinando compromisos, obligaciones y beneficios mutuos. Convenir la contribución económica con los usuarios e interesados, aplicarla en obras licitadas y comprobables. Formalizar la fundación de conservación ambiental de cada uno de los parques urbanos. Diligenciar las fuentes de financiamiento y recursos económicos concurrentes para la ejecución, seguimiento y evaluación de resultados.

\section{Competencia concientización y educación ambiental}

Divulgación de los bienes y servicios ambientales que brindan los parques urbanos y las áreas verdes a través de medios impresos y electrónicos. Promover la campaña anual para la conservación de los parques y áreas verdes. Inducir información visual y escrita básica que deben conocer los usuarios sobre las medidas de conducta y protección previamente al ingresó en un parque urbano. Promover la ciencia ciudadana por medio de talleres y actividades dirigidas a distintos niveles de edad sobre ocio activo y medioambiente, observación de flora y fauna, separación de residuos, interpretación de la naturaleza, salud ambiental, energía, consumo ecológico, espacios protegidos, conservación y rehabilitación de espacios verdes.

\section{Competencia de función pública}

La inserción de las competencias operativas requiere leyes y políticas de observancia territorial, que incorporen la 
certeza jurídica de la función ecológica de las áreas verdes al sistema de decisiones que anticipen el estado ambiental de los componentes biofísicos, infraestructurales, la conservación, protección y rehabilitación en la operación, así mismo la instrucción formal e informal situada que vehicule las actitudes y las conductas que fortalezcan la aptitud social para mejorar y conservar las funciones de los parques urbanos y las áreas verdes urbanas.

\section{Conclusión}

El estudio escala la aptitud social por medio de la indagación empírica del patrón perceptual y el valor de importancia que los usuarios otorgaron al contexto y a las funciones ambientales del Parque Metropolitano Bicentenario en la ciudad de Toluca.

Los enfoques teóricos destacan la comprensión socio cultural basada en las creencias, los significados, las normas y las representaciones sociales que identifican la valoración y la afectividad como propiedades inherentes a las personas y a las culturas propias, lo cual se expresa en el modo de relacionamiento con el entorno natural y social, y en las expectativas para responder a la imbricación y cambios de los contextos en los que se vive.

En el plano subjetivo los valores, los afectos, las emociones y los modos de adquisición del conocimiento, percepción sensible y formación escolar, impulsan actitudes que tienen función afectivo-valorativa, esta propiedad modula la influencia de las motivaciones en las conductas que visibilizan las relaciones con el ambiente, en dirección positiva o negativa.

Los resultados confirman que la aptitud social de la percepción ambiental es una capacidad adaptativa que puede ser construida, potenciada o inhibida por factores socioculturales e individuales. Es imprescindible cambiar aspectos arraigados en la idiosincrasia y avanzar hacia conductas asertivas que se manifiestan como síntesis de sentimientos, pensamientos, conocimiento y necesidades, respetando los derechos de los demás y del medioambiente.

En el caso de estudio el patrón perceptual de los usuarios incorpora experiencias, información y conocimiento ambiental, los juicios de valor o de importancia que involucran a los otros expresan apreciación general de las conductas negativas sobre el medioambiente. La ausencia de juicios sobre el bienestar colectivo, crecimiento económico y desequilibrio ambiental expresa bajo nivel de empatía e intersubjetividad social, lo cual se atribuye a los conflictos que producen los valores aprendidos, la formación ambiental escolarizada inconexa de las emociones y la vida cotidiana, y al estrés derivado de la proximidad de los problemas económicos y personales. La ausencia de participación activa generalizada, en el hogar y en el parque urbano, sugieren estados afectivos de neutralidad o indiferencia que exhiben la debilidad del compromiso ambiental.

Sin embargo, el reconocimiento, discernimiento y valoración positiva del estado físico y las funciones ambientales del parque urbano, expresa fuerte disposición pro ambiental, la cual se caracteriza por la identificación de la importancia de los servicios ambientales que prestan las áreas verdes, la valoración positiva y satisfactoria de las cualidades y los beneficios ambientales, deportivos, recreativos y en la salud, la socialización de la responsabilidad intencionada, la disposición al pago y el interés por aprender temas ambientales cercanos a la vida cotidiana.

El procesamiento de los juicios de valor que conjugan factores emocionales, sensoriales, aprendidos $y$ racionales para proponer, elegir, ordenar y jerarquizar las opciones de mejora, destacan las acciones socio organizativas, la participación social, cumplimiento de las normas de conducta y en su caso aplicación de sanciones.

El núcleo generador de la capacidad social adaptativa articula la fuerte disposición proambiental, la selección y jerarquización de opciones de mejora que implican necesidades y expectativas de responsabilidad ambiental y la participación social vinculada al bienestar emocional de la recreación, el deporte, beneficios de salud.

Dada cuenta que las actitudes proambientales no se traducen siempre en conductas activas en beneficio o mejora de condiciones ambientales preexistentes. La operación de las áreas de oportunidad identificadas de la percepción ambiental depende del sistema de decisión que organiza los procesos de cooperación y negociación, los programas y proyectos de mejora continua y el marco regulatorio para la gestión socio ecológica de las áreas verdes en la ciudad de Toluca [B] 


\section{Bibliografía}

Alea, A. (2006). Diagnóstico y potenciación de la educación ambiental en jóvenes universitarios. Odiseo, Revista electrónica de Pedagogía, (6), 1-29. http://www.scielo.org.co/scielo.php?script=sci nlinks \&ref $=000088 \&$ pid $=$ S0120$0534201300030001300001 \& \operatorname{lng}=\mathrm{en}$

Álvarez, P. y Vega, P. (2010). Actitudes ambientales y conductas sostenibles. implicaciones para la educación ambiental. Revista de Psicodidáctica, 14(2), 245-260.

https://www.ehu.eus/ojs/index.php/psicodidactica/a rticle/view $/ 727 / 603$

Arista, I. A. (2008). ¿Qué saben y Cómo aprenden los niños sobre el valor de la Selva en la isla de Cozumel? Un análisis desde el hogar, la escuela y la comunidad. Morelia: Centro de Investigación en Ecosistemas. Universidad Nacional Autónoma de México.

Barberousse, P. (2008). Fundamentos teóricos del Pensamiento complejo de Edgar Morin. Revista Electrónica Educare, 12(2), 95-113. https://doi.org/10.15359/ree.12-2.6

Barrón, C. e Ysunza, M. (2003). Currículum y formación profesional. En La investigación curricular en México. La década de los noventa. En Díaz Barriga, A. (coord.). Consejo Mexicano de Investigación Educativa, SEP/CESU, Colección La Investigación Educativa en México 1992-2002 (pp. 125-162). México-Distrito Federal.

Briceño, J. y Ribas, Y. (2012). La realidad que envuelve el ser desde la perspectiva del pensamiento complejo. Educere, 16(55),267-271.

Cabezas, M. M. (2010). Autonomía y emocionalidad en el agente moral. Revista de Filosofía Factótum, (7), 7685. http://www.revistafactotum.com/revista/f 7/articulo s/Factotum 7 7 Mar Cabezas.pdf

Candela, A., Sánchez, A. y Alvarado, C. (2012). Las ciencias naturales en las reformas curriculares. La enseñanza de la ciencia en la educación básica en México. En Fernando Flores-Camacho (Coord.), Instituto Nacional para la Evaluación de la Educación, (pp. 11-32). México- Distrito Federal.

Capel, H. (1973). Percepción del medio y comportamiento geográfico. Revista de geografía, 7(1), 58-150. https://www.raco.cat/index.php/RevistaGeografia/ar ticle/view/45873
Cendra, J. y Paolini, J. (2015). Evaluación del cambio de percepción ambiental en los estudiantes del master en sostenibilidad de la UPC a partir de las dimensiones del nuevo paradigma ecológico. II Congreso UPC Sostenible 2015. Barcelona- España.

Cerati, T. M. y Queiroz, A. (2016). Participación social en la gestión ambiental: estudio de caso en una unidad de conservación urbana en el municipio de São Paulo, Brasil. Estudios demográficos urbano, 31(1), 87-113. http://www.scielo.org.mx/scielo.php?script=sci artte xt\&pid=S0186-72102016000100087\&lng=es\&nrm=iso

Ciompi, L. (2007). Sentimientos, afectos y lógica afectiva: Su lugar en nuestra comprensión del otro y del mundo. Revista de la Asociación Española de Neuropsiquiatría, 27(2), 153-171. http://scielo.isciii.es/scielo.php?script=sci arttext\&pi $\mathrm{d}=$ S0211-57352007000200013\&Ing=es\&tlng=es.

Consejo Nacional de Población [CONAPO]. (2010). Delimitación de las Zonas Metropolitanas de México. http://www.conapo.gob.mx/es/CONAPO/Zonas metr opolitanas 2010

Contreras, F. y Esguerra, G. (2006). Psicología positiva: una nueva perspectiva en psicología. Diversitas, 2(2), 311-319.

http://pepsic.bvsalud.org/scielo.php?script=sci_artte xt\&pid=S1794-99982006000200011\&lng=pt\&tlng=es.

Coordinación General de Conservación Ecológica, Delegación Regional Toluca [CGCERT]. (2017). Afluencia del Parque Metropolitano Bicentenario 2013-2018. Toluca-México: Secretaría del Medio Ambiente del Estado de México.

Covarrubias, P. (2018). Del concepto de aptitudes sobresalientes al de altas capacidades y el talento. IE Revista de investigación educativa de la REDIECH, 9(17), 53-67. http://dx.doi.org/10.33010/ie rie rediech.v9i17

Cuervo, L. (2010). Percepción y conocimiento ambiental del sitio Ramsar 1602: "Manglares y Humedales de Tuxpan". Veracruz, México: Universidad Veracruzana, México.

Díaz, F. (2006). Enseñanza situada: vínculo entre la escuela y la vida. México-Distrito Federal: Mc Graw Hill/ Interamericana editores, S.A. DE C.V. 
Durán, M., Álzate, M., López, W. y Sabucedo, J. M. (2007). Emociones y comportamiento proambiental. Revista Latinoamericana de Psicología, 39(2), 287-296, http://pepsic.bvsalud.org/scielo.php?script=sci_artte xt\&pid=S0120-05342007000200006\&lng=pt\&tlng=es.

Falcón, A. (2007). Espacios verdes para una ciudad sostenible. Barcelona: Gustavo Gilli.

Febles, M. (2001). Hacia un enfoque holístico del Medio Ambiente desde la Psicología Ambiental. Cuba: Universidad de La Habana.

Fernández, Y. (2008). ¿Por qué estudiar las percepciones ambientales? Una revisión de la literatura mexicana con énfasis en Áreas Naturales Protegidas. Espiral, Estudios sobre Estado y Sociedad, XV(43), 179-202. http://www.scielo.org.mx/pdf/espiral/v15n43/v15n4 3a6.pdf

Flores, R. (2012). Incorporando desarrollo sustentable y gobernanza a la gestión y planificación de áreas verdes urbanas. Frontera Norte, 24(48), 165-190. http://www.scielo.org.mx/pdf/fn/v24n48/v24n48a7. pdf

Flores, R. y González, M. J. (2010). Planificación de sistemas de áreas verdes y parques públicos de algunas ciudades del mundo, Revista Mexicana de Ciencias Forestales, 1(1), 17-24.

http://www.scielo.org.mx/scielo.php?script=sci artte xt\&pid=S2007-11322010000100003\&lng=es\&tlng=es.

García, L. y Restrepo, A. (2015). Desarrollo humano y social en las prácticas ambientales de los graduados de la Maestría en Desarrollo Sostenible y Medio ambiente, Revista Virtual Universidad Católica del Norte, (44), 253-266.

http://revistavirtual.ucn.edu.co/index.php/RevistaUC N/article/view/628/1163

García, S., Guerrero, M. (2006). Indicadores de sustentabilidad ambiental en la gestión de espacios verdes. Parque urbano Monte Calvario, Tandil, Argentina. Revista de Geografía Norte Grande, (35), 45-57.

https://scielo.conicyt.cl/scielo.php?script=sci abstrac $\underline{\mathrm{t} \& \mathrm{pid}=S 0718-34022006000100004 \& \operatorname{lng}=\mathrm{es} \& \mathrm{nrm}=\mathrm{iso}}$

Giménez, G. (1999). La Investigación Cultural en México. Una aproximación. Perfiles Latinoamericanos, 8(15), 119-138.

https://perfilesla.flacso.edu.mx/index.php/perfilesla/ article/view/356
Gomera, A. (2008). La conciencia ambiental como herramienta para la educación ambiental: conclusiones y reflexiones de un estudio en el ámbito universitario. Córdoba: Centro Nacional de Educación Ambiental, Universidad de Córdoba.

https://www.miteco.gob.es/ca/ceneam/articulos-deopinion/2008 11gomera1 tcm34-163624.pdf

Gómez, T. (2010). Conciencia ecológica, pensamiento económico y una mirada marxista compleja. Revista Venezolana de Economía y Ciencias Sociales, 16(2),1327. https://www.redalyc.org/articulo.oa?id=177/1773 $\underline{1129002}$

Guerra, M. T. (2012). El currículo oficial de ciencias para la educación básica y sus reformas recientes: retórica y vicisitudes, La enseñanza de la ciencia en la educación básica en México. En Fernando FloresCamacho (Coord.), Instituto Nacional para la Evaluación de la Educación (pp. 79-92). MéxicoDistrito Federal.

Gutiérrez Vera, D. (2003). Figuras del sujeto. Pedagogía $Y$ Saberes, (18), 21-32. https://doi.org/10.17227/01212494.18pys21.32

H. Ayuntamiento municipio de Toluca. (2013). Inventario de áreas verdes del municipio de Toluca, 2013. Dirección de medio ambiente y servicios públicos. Toluca, México.

173

H. Ayuntamiento de Toluca. (2013). Plan municipal de desarrollo urbano de Toluca 2013-2015. México.

Hernández R., Fernández, C. y Baptista, P. (2014). Metodología de la Investigación. México: Editorial Mc Graw Hill.

Herrera, J. y Zamora, N. (2014). ¿Sabemos realmente que es la motivación? Correo Científico Médico, 18(1), 126-128.

http://scielo.sld.cu/scielo.php?script=sci_arttext\&pid =S1560-43812014000100017\&lng=es\&tlng=es.

Instituto Nacional de Estadística, Geografía e Informática. [INEGI]. (2015). Características del entorno urbano 2014.

http://www.beta.inegi.org.mx/proyectos/encotras/cl eu/2014/

Instituto Nacional de Estadística, Geografía e Informática. [INEGI]. 2016). Inventario Nacional de Viviendas 2016. http://www.beta.inegi.org.mx/app/mapa/inv/

Laca, F. A. (2005). Actitudes y comportamientos en las situaciones de conflicto. Enseñanza e Investigación en Psicología, 10(1),117-

126. https://www.redalyc.org/articulo.oa?id=292/292 10108 
Lupano, M. L; Castro, A. (2010). Psicología positiva: análisis desde su surgimiento. Ciencias Psicológicas, IV(1), 43-56.

http://www.scielo.edu.uy/scielo.php?script=sci artte xt\&pid=S1688-42212010000100005\&lng=es\&tlng=es.

Mañon De la Cruz, R., Orozco, E., Mireles, P. (2018). Evaluación de los servicios ambientales del Parque Metropolitano Bicentenario, Toluca, México. Revista Iberoamericana de Ciencias, 5(3), 51-66. http://www.reibci.org/jun-18.html

Marrón, M. J. (1999). La geografía del comportamiento y de la percepción. aportaciones a la investigación y a la enseñanza de la geografía. Didáctica Geográfica, 2(3), 85-108. http://www.age-

geografia.es/didacticageografica/index.php/didactica geografica/article/download/152/150.

Mikulic, I. M., Cassullo, G. L., Albornoz, O., Marconi, A., Fernández, G., Ojeda, G. M, García Labandal, L. B, Pierri, J., Prilucas, C., Torcassi, V., Elmasian, M. y Caruso, A. (2009). Psicología ambiental y evaluación psicológica: aportes de las técnicas psicométricas a la evaluación de la percepción del riesgo. En I Congreso Internacional de Investigación y Práctica Profesional en Psicología XVI Jornadas de Investigación Quinto Encuentro de Investigadores en Psicología del MERCOSUR (pp. 511-513). Universidad de Buenos Aires, Buenos Aires. http://www.aacademica.org/000-020/762

Millennium Ecosystem Assessment (MEA). (2005). Ecosystems and human wee-being synthesis, Island Press. United States of America: Island Press. http://www.millenniumassessment.org/es/Framewor k.html

Morales, F. J. (2012). la geografía de la percepción: una metodología válida aplicada al caso de una ciudad de tipo medio-pequeño. El ejemplo de yecla (Murcia). Papeles de Geografía (55-56), 137-152. https://revistas.um.es/geografia/article/view/176261 $\angle 148741$

Morales, J. P. (2011). Notas conceptuales. La capacidad de carga: conceptos y usos. Recursos Naturales y Ambiente (63), 47-53. CATIE, Sede Central. Costa Rica. http://repositorio.bibliotecaorton.catie.ac.cr/bitstrea $\mathrm{m} /$ handle/11554/6445/7.\%20Morales.pdf?sequence= 1\&isAllowed=y
Noguera de Echeverri, A. (2007). Complejidad ambiental: propuestas éticas emergentes del pensamiento ambiental latino-americano. Gestión y

Ambiente, 10(1), 5-30.

https://www.redalyc.org/articulo.oa?id=1694/16941 9796001

Organización de las Naciones Unidas [ONU]. (2017). La Nueva Agenda Urbana. Secretariado de Hábitat III. http://onuhabitat.org.mx/index.php/la-nuevaagenda-urbana-en-espanol

Organización Mundial de la Salud [OMS]. (2018). Actividad física. https://www.who.int/es/newsroom/fact-sheets/detail/physical-activity

Ostrom, E. (2000). Diseños complejos para manejos complejos. Gaceta Ecológica, (54), 43-58. https://www.redalyc.org/articulo.oa?id=539/539054 $\underline{04}$

Padilla y Sotelo, L. y Luna Moliner, A. (2012). Percepción y conocimiento ambiental en la costa de Quintana Roo: una caracterización a través de encuestas. Revista Investigaciones Geográficas, (52), 99-116. http://dx.doi.org/10.14350/rig.30335

Parales, C.J. y Vizcaíno, M. (2007). Las relaciones entre actitudes y representaciones sociales: elementos para una integración conceptual. Revista Latinoamericana de Psicología, 39(2), 351-361.

http://pepsic.bvsalud.org/scielo.php?script=sci artte xt\&pid=S0120-05342007000200010\&lng=pt\&tlng=es.

Rivera, M. y Rodríguez, C. (2009). Actitudes y comportamientos ambientales en estudiantes de enfermería de una universidad pública del norte del Perú. Revista Perú Medicina. Salud Publica 26(3), 338342.

http://www.scielo.org.pe/pdf/rins/v26n3/a12v26n3.p df

Rizo, M. (2006). George Simmel, sociabilidad e interacción. aportes a la ciencia de la comunicación. Cinta de Moebio, (27),43-60. https://cintademoebio.uchile.cl/index.php/CDM/artic le/view/25941/27254

Roth, E. (2000). Psicología ambiental: interfase entre conducta y naturaleza. Revista Ciencia y Cultura, (8), 63-78.

http://www.scielo.org.bo/scielo.php?script=sci artte xt\&pid=S2077-33232000000200007\&Ing=es\&t|ng=es

Secretaria de Desarrollo Social [SEDESOL]. (1999). Sistema normativo de equipamiento urbano, Tomo $\mathrm{V}$. Recreación y deporte, Distrito Federal. México: SEDESOL. 
Sierra, R. (1995). Técnicas de investigación Social. Teoría y ejercicios. Madrid: editorial Paraninfo.

Tabara, J. (2018). La medida de la percepción social del medio ambiente. Una revisión de las aportaciones realizadas por la sociología. Revista Internacional de Sociología, 59(28), 127-171.

http://dx.doi.org/10.3989/ris.2001.i28.745

Tito, O., Velázquez, D. L., Fermorselle, D., Martínez, L., Cos, L. (2013). Psicología y pensamiento complejo. Revista Información Científica, 80(4), 110. http://www.revinfcientifica.sld.cu/index.php/ric/a rticle/view/938/2849

Uribe, M. L. (2014). La vida cotidiana como espacio de construcción social. Procesos Históricos, (25),100-113, http://erevistas.saber.ula.ve/index.php/procesoshist oricos/article/view/9772/9706

Valadez, A., Landa, P. (2002). Investigaciones cualitativas en el ámbito de la psicología ambiental: una revisión bibliográfica. Revista Electrónica de Psicología Iztacala, 5(2), 2-17. http://revistas.unam.mx/index.php/repi/article/view/ 22666/21405INVESTIGACIONES

Valera, S., Pol, E. y Vidal, T. (2015). Elementos básicos de psicología ambiental. España:_Universidad de Barcelona.
Vargas, A., Roldán, P. (2018). Ni muy cerca ni muy lejos: parques urbanos y bienestar subjetivo en la ciudad de Barranquilla, Colombia. Lecturas de Economía, (88), 183-205. http://dx.doi.org/10.17533/udea.le.n88a06

Vargas, L. M. (1994). Sobre el concepto de percepción. Revista Alteridades, 4(8), 47-53. https://doi.org/10.24275/alte.v0i8

Vélez, L. (2009). Del parque urbano al parque sostenible. Bases conceptuales y analíticas para la evaluación de la sustentabilidad de parques urbanos, Revista de Geografía Norte Grande, 43(1), 31-49. http://dx.doi.org/10.4067/S071834022009000200002

Walker, M. (2011). ¿Aptitudes y qué más? Principios para las pedagogías de praxis en la educación superior. Universitas, 15(2), 85-107. https://doi.org/10.17163/uni.n15.2011.03

Zamorano, B., Parra, V., Peña, F., Castillo, Y., y Vargas, J. I. (2009). Percepción ambiental en estudiantes de secundaria. Actualidades Investigativas en Educación, 9(3), 1-19. https://revistas.ucr.ac.cr/index.php/aie/article/view/ $\underline{17999}$ 